\title{
Macromolecular Chiral Amplification through Random Coil to One-Handed Helix Transformation Induced by Metal Ion Coordination in Aqueous Solution
}

Huajun Huang, ${ }^{1}$ Huimin Duan, ${ }^{1}$ Lijie Yin, ${ }^{1}$ Dongming Qi, ${ }^{1 *}$ Jiadan Xue, ${ }^{2}$ Yingjie Zhang, ${ }^{3}$ Jianping Deng ${ }^{3 *}$

${ }^{1}$ Key Laboratory of Advanced Textile Materials and Manufacturing Technology, School of Materials Science and Engineering \& School of Textile Science and Engineering, Zhejiang Sci-Tech University, Hangzhou 310018, China

${ }^{2}$ Department of Chemistry, Zhejiang Sci-Tech University, Hangzhou, 310018, China

${ }^{3}$ College of Materials Science and Engineering, Beijing University of Chemical Technology, Beijing 100029, China 


\section{Contents}

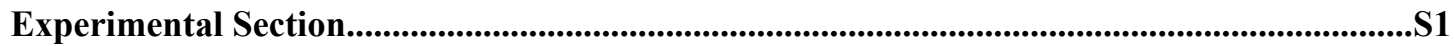

FT-IR \& NMR Spectra of the Monomer (M-L-ala-Boc) ...........................................................S8

FT-IR \& NMR Spectra of the Polymers.............................................................................

GPC Curves of the Polymers ..................................................................................................................515

Characterization of M-L-ala- $\mathrm{NH}_{2}$ and its "Polymerization" Products ......................................S16

CD and UV-vis Absorption Spectra of the Polymers ...............................................................S17

CD and UV-vis Absorption Spectra of the Metal Chlorides......................................................S20

DLS and GPC Analysis of the Helical Chirality Induction Process ..........................................S20

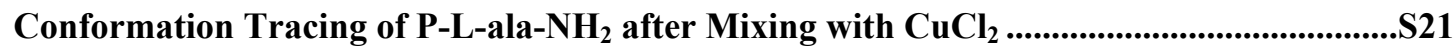

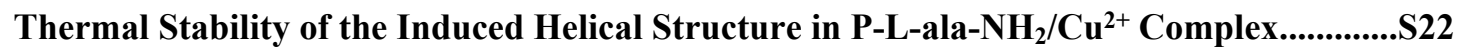

CD and UV-vis Absorption Spectra of the Copper ( II ) Salts ......................................................S23

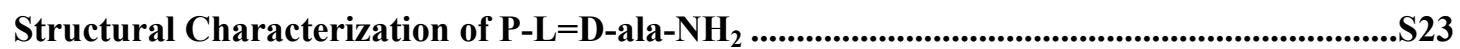

Specific Rotations of Some Important Samples Prepared in This Work .................................S24

Thermal Stability of the Induced Helical Structure in P-L-ala- $\mathrm{NH}_{2} / \mathbf{A g}^{+}$Complex ...............S25

$\mathrm{CD}$, UV-vis Absorption, and NMR Spectra of the P-L-ala- $\mathrm{NH}_{2}$ and $\mathrm{CuCl}_{2}$ Mixtures with

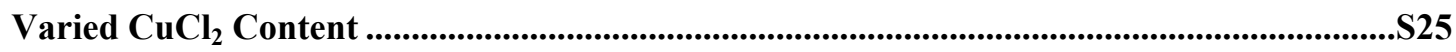

Resonance Raman Spectra of Pure Polymers ....................................................................................S27

Resonance Raman Spectra (Full Graph), DSC Traces, XRD Patterns, and FT-IR Spectra of the P-L-ala- $\mathrm{NH}_{2}$ and $\mathrm{CuCl}_{2}$ Mixtures with Varied $\mathrm{CuCl}_{2}$ Content ..........................................S28

$\mathrm{CD}$ and UV-vis Absorption Spectra of P-L-ala- $\mathrm{NH}_{3}{ }^{+} \mathrm{TFA}^{-}$in the Presence of $\mathrm{Ag}^{+}$.................S31

Effect of pH on the Induced Helical Structure ….....................................................................S32

CD and Vis-NIR Absorption Spectra of M-L-ala- $\mathrm{NH}_{2} / \mathrm{Cu}^{2+}, \mathrm{M}-\mathrm{D}-\mathrm{ala}-\mathrm{NH}_{2} / \mathrm{Cu}^{2+}$, and

D-alaninamide $/ \mathrm{Cu}^{2+}$ Complexes ...........................................................................................................53

Effect of Metal Scavenger and Dilution on the Induced Helical Structure..............................S33

Supporting References and Notes ...................................................................................................536 


\section{Experimental Section}

Materials. $\mathrm{Rh}$ catalyst, (nbd) $\mathrm{Rh}{ }^{+} \mathrm{B}-\left(\mathrm{C}_{6} \mathrm{H}_{5}\right)_{4}$ was prepared according to the literature. ${ }^{1}$ Boc-L-alanine and Boc-D-alanine were bought from Sigma-Aldrich. The other reagents were purchased from Aladdin. All the reagents were directly used without further purification. Deionized water was used for the helical chirality induction experiments and all the measurements that need water as solvent. Organic solvents, including $\mathrm{CH}_{2} \mathrm{Cl}_{2}$ (DCM), $\mathrm{CHCl}_{3}$ (TCM), toluene (Tol), $\mathrm{CH}_{3} \mathrm{CH}_{2} \mathrm{OH}$ (EtOH), $\mathrm{CH}_{3} \mathrm{OH}(\mathrm{MeOH})$, tetrahydrofuran (THF), N,N-Dimethylformamide (DMF), dimethyl sulfoxide (DMSO), ethyl acetate (EA), and $n$-hexane, were distilled under reduced pressure and dried by molecular sieve before use.

Measurements. Circular dichroism (CD) and UV-vis absorption spectra were measured using an Olis DSM 172 spectrophotometer equipped with a peltier temperature controller and a water-circulating temperature controller. Dynamic light scattering (DLS) experiments were performed on a Malvern Zetasizer Nano ZS90 instrument. FT-IR spectra were recorded using a Nicolet 5700 infrared spectrometer ( $\mathrm{KBr}$ tablet). NMR spectra were recorded on a Bruker AV 400 spectrometer. Elemental analysis was performed on an Elementar vario MICRO cube element analyzer. The relative molecular weight and polydispersity index of P-L-ala-Boc were determined using THF as eluent by a WATERS 515 GPC equipped with a Shim-pack GPC-804 column and calibrated with polystyrenes. The relative molecular weight and polydispersity index of $\mathrm{P}$-L-ala- $\mathrm{NH}_{2}$ were determined using the aqueous solution $(\mathrm{pH}$ 
$=4.2)$ of $\mathrm{CH}_{3} \mathrm{COONa}(0.1 \mathrm{M})$ and $\mathrm{CH}_{3} \mathrm{COOH}$ as eluent by a WATERS $1525 \mathrm{GPC}$ equipped with a TSKgel G4000PWxL column and calibrated with dextrans. Differential scanning calorimetry (DSC) curves were obtained in $\mathrm{N}_{2}$ atmosphere at a heating rate of $10^{\circ} \mathrm{C} \mathrm{min}^{-1}$ using a TA DSC Q2000 differential scanning calorimeter. X-ray photoelectron spectra (XPS) were measured by a Thermo Scientific K-Alpha XPS system. X-ray diffraction (XRD) analyses were performed on a Thermo Scientific ARL X'TRA powder diffractometer with $\mathrm{CuK}_{\alpha}$ radiation source. Optical rotations were recorded with a JASCO P-2000 digital polarimeter (sodium D-line, 589 $\mathrm{nm})$. The $\mathrm{pH}$ values were determined by a METTLER TOLEDO S220-UMIX $\mathrm{pH}$ meter.

Resonance Raman spectra were acquired with a homemade resonance Raman spectroscopic apparatus described previously. ${ }^{2}$ The $341.5 \mathrm{~nm}$ laser pulses were obtained from the Stokes Raman scattering of hydrogen Raman-shifted lines from the forth harmonics of a Nd:YAG Q-switched laser with the pulse width of $10 \mathrm{~ns}$. The excitation laser beam was focused onto the quartz cuvette loaded with aqueous solution of the sample using a near-collinear geometry. The Raman-scattered light was collected in a backscattering geometry and detected by a liquid nitrogen-cooled CCD. The Raman signal was read by an connected PC, and the spectra were calibrated by utilizing the known wavenumbers of acetonitrile Raman bands to an absolute accuracy of about $\pm 3 \mathrm{~cm}^{-1}$ (and a relative accuracy of 1-2 $\mathrm{cm}^{-1}$ from scan to scan).

Preparation of M-L(or -D)-ala-Boc. Both M-L-ala-Boc and M-D-ala-Boc have 
been synthesized previously by Masuda et al., ${ }^{3,4}$ while we in the present work prepared them in a different way, as described below.

Boc-L(or -D)-alanine (3.8 g, $20 \mathrm{mmol})$, isobutyl chloroformate $(2.6 \mathrm{~mL}, 20 \mathrm{mmol})$, and 4-methylmorpholine $(2.2 \mathrm{~mL}, 20 \mathrm{mmol})$ were sequentially dissolved in anhydrous THF $(\sim 80 \mathrm{~mL})$ under magnetic stirring at $30^{\circ} \mathrm{C}$. A slightly excessive amount of propargylamine $(1.35 \mathrm{~mL}, 21 \mathrm{mmol})$ was then added into the solution with a dropping funnel in $10 \mathrm{~min}$. After reacting under magnetic stirring at $30^{\circ} \mathrm{C}$ for $4 \mathrm{~h}$, the white precipitate was filtered off, and the filtrate was diluted by a large amount of EA $(\sim 100$ $\mathrm{mL}$ ). The as-obtained solution was washed with $2 \mathrm{M} \mathrm{HCl}$ aqueous solution and saturated $\mathrm{NaHCO}_{3}$ aqueous solution sequentially, dried over anhydrous $\mathrm{MgSO}_{4}$, and concentrated by rotary evaporation to result in the coarse product. After purifying the coarse product by recrystallization thrice from $\mathrm{THF} / n$-hexane, colorless lamellar crystals of M-L(or -D)-ala-Boc was obtained in high yield (73\%).

Elemental analysis of M-L-ala-Boc: Anal. Calcd for $\mathrm{C}_{11} \mathrm{H}_{18} \mathrm{~N}_{2} \mathrm{O}_{3}$ : C, 58.39; H, 8.02; N, 12.38. Found: C, 58.41; H, 7.95; N, 12.33 .

Preparation of M-L-ala- $\mathbf{N H}_{2} \cdot$ M-L-ala- $\mathrm{NH}_{2}$ was prepared through the $N$-Boc deprotection of M-L-ala-Boc followed by a deprotonation process (Scheme S1), as described in detail below. A predetermined amount of M-L-ala-Boc ( $\sim 5 \mathrm{mmol})$ was added into an EA solution of $\mathrm{HCl}\left(\sim 4 \mathrm{~mol} \mathrm{~L}^{-1}, 20 \mathrm{~mL}\right)$, and the as-obtained mixture was stirred at $0^{\circ} \mathrm{C}$ for $2 \mathrm{~h}$ and then at $30^{\circ} \mathrm{C}$ overnight for $N$-Boc deprotection reaction. The resulted solution was concentrated by rotary evaporation to eliminate most solvent and $\mathrm{HCl}$, and then diluted by large amount of $\mathrm{EtOH}$ and vigorously stirred 
with $\mathrm{K}_{2} \mathrm{CO}_{3}$ powder for $15 \mathrm{~min}$ to eliminate the residual $\mathrm{HCl}$ and deprotonate the amino groups. After filtering off the solids, the final product (i.e. M-L-ala-NH $\mathrm{N}_{2}$, a colorless sticky liquid soluble in water, DMSO, methanol, and ethanol, while almost insoluble in other common solvents) was obtained by completely drying the filtrate.

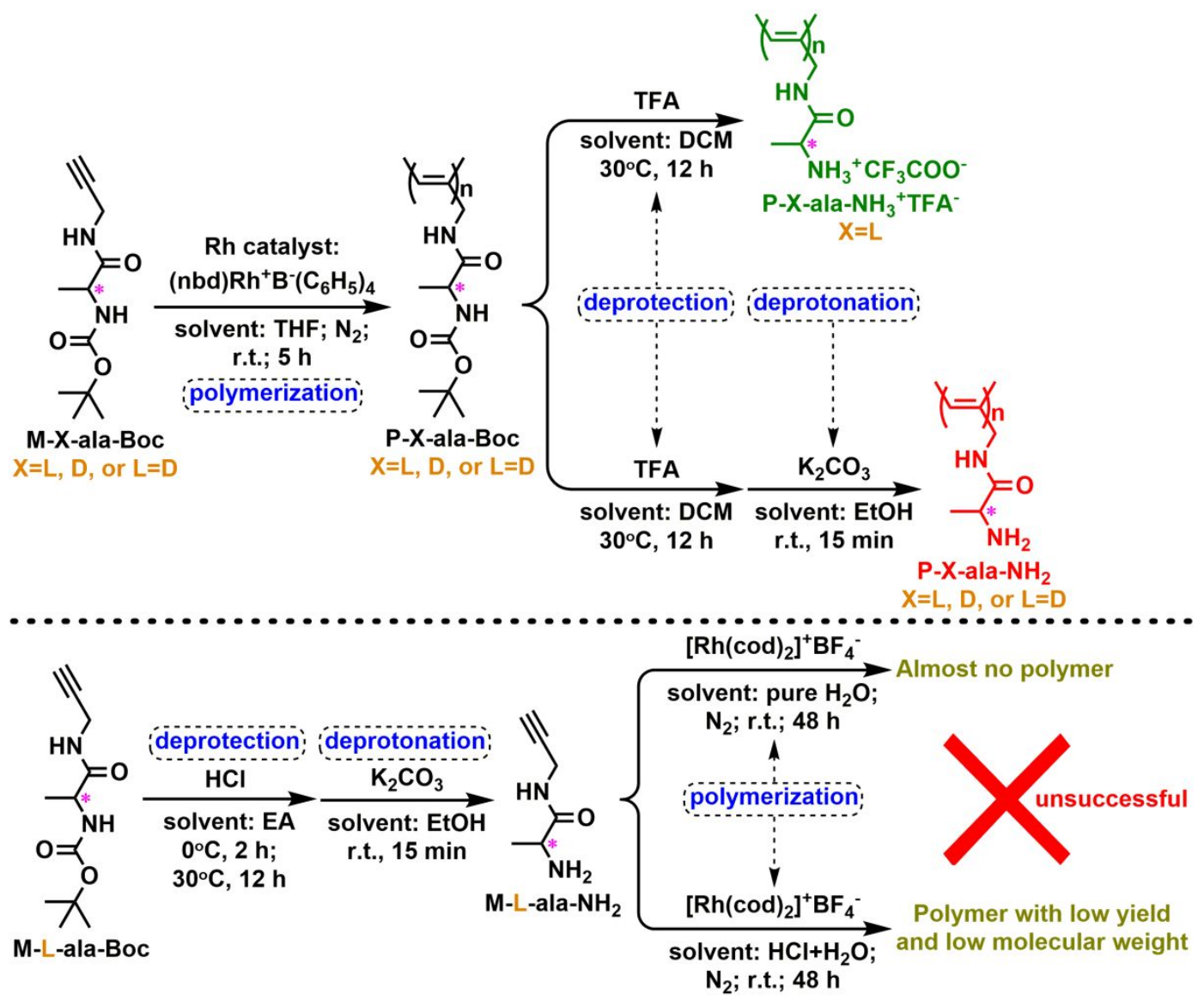

Scheme S1. Schematic illustration for the polymer preparation in this work.

The structures and synthetic routes of polymers mentioned in this work were shown in Scheme S1, and the detailed preparation methods were summarized as follows.

Preparation of P-X-ala-Boc. The polymerization behavior of M-L-ala-Boc has been studied in detail by Masuda et al., ${ }^{3}$ and thus we in the present work prepared P-L(or -D)-ala-Boc in only one predetermined condition, as briefly described below. 
A THF solution of M-L(or -D)-ala-Boc $\left(0.2 \mathrm{~mol} \mathrm{~L}^{-1}\right)$ was added into the reaction tube loaded with Rh catalyst ( $1 \mathrm{~mol} \%$ of $\mathrm{M}-\mathrm{L}$ (or $-\mathrm{D})$-ala-Boc) under $\mathrm{N}_{2}$ protection. The polymerization reaction was then conducted in a water bath at $30^{\circ} \mathrm{C}$ for over $5 \mathrm{~h}$, resulting in a dark orange solution. After pouring the solution into a large amount of $n$-hexane $(\mathrm{THF} / n$-hexane $\approx 1 / 6(\mathrm{v} / \mathrm{v}))$, a flocculent precipitate formed immediately. It was filtered, reprecipitated twice from $\mathrm{THF} / n$-hexane, and dried in vacuum to give orange powder-like P-L(or -D)-ala-Boc in $92.9 \%$ yield.

$\mathrm{P}-\mathrm{L}=\mathrm{D}$-ala-Boc was also synthesized in the above way but using the equimolar mixture of M-L-ala-Boc and M-D-ala-Boc as monomer. The yield of P-L=D-ala-Boc (white to pale yellow powder) was $91.5 \%$.

Preparation of P-X-ala- $\mathbf{N H}_{2}$. The $\mathrm{N}$-Boc deprotection reaction of $\mathrm{P}-\mathrm{X}$-ala-Boc was conducted by adding an excessive amount of trifluoroacetic acid (TFA; TFA/monomer unit $\approx 30 / 1(\mathrm{~mol} / \mathrm{mol}))$ into the DCM solution of P-X-ala-Boc $(\sim 0.05 \mathrm{~g}$ $\left.\mathrm{mL}^{-1}\right)$ and then stirring the resulting mixture at $30^{\circ} \mathrm{C}$ for $12 \mathrm{~h}$ (A sticky precipitate was gradually formed after the addition of TFA). The reaction system was subjected to rotary evaporation for eliminating most of TFA, and the thus-formed semi-solid was dissolved in a large amount of EtOH and vigorously stirred in the presence of $\mathrm{K}_{2} \mathrm{CO}_{3}$ powder for 15 min to eliminate the residual TFA and deprotonate $-\mathrm{NH}_{3}{ }^{+}$. Afterwards, the solid was filtered off, and the concentrated filtrate was diluted with EA (EA/EtOH $\approx 10 / 1(\mathrm{v} / \mathrm{v}))$ to cause a precipitation. The precipitate was centrifuged and vacuum dried to turn into powder-like $\mathrm{P}-\mathrm{X}$-ala- $\mathrm{NH}_{2}$ with a white to pale yellow color.

The weight ratio of the obtained $\mathrm{P}-\mathrm{X}$-ala- $\mathrm{NH}_{2}$ to the pristine $\mathrm{P}-\mathrm{X}$-ala-Boc is almost 
equal to the repeating unit molecular weight ratio of $\mathrm{P}-\mathrm{X}-$-ala- $\mathrm{NH}_{2}$ to $\mathrm{P}-\mathrm{X}$-ala-Boc.

Preparation of P-L-ala- $\mathbf{N H}_{3}{ }^{+} \mathbf{T F A}-$ The method for synthesizing P-L-ala- $\mathrm{NH}_{3}{ }^{+} \mathrm{TFA}^{-}$was almost the same as that for synthesizing P-X-ala- $\mathrm{NH}_{2}$, except for its absence of deprotonation process. The semi-solid obtained by rotary evaporating the $\mathrm{N}$-Boc deprotection reaction system was dissolved in a small amount of EtOH and diluted with EA to precipitate $\mathrm{P}-\mathrm{L}-$ ala- $\mathrm{NH}_{3}{ }^{+} \mathrm{TFA}^{-}$directly $(\mathrm{EA} / \mathrm{EtOH} \approx$ $10 / 1(\mathrm{v} / \mathrm{v}))$. The precipitate was centrifuged and vacuum dried to turn into white to pale yellow fine powder that looks quite like $\mathrm{P}-\mathrm{X}-$ ala- $\mathrm{NH}_{2}$.

The weight ratio of the obtained $\mathrm{P}-\mathrm{L}-\mathrm{ala}-\mathrm{NH}_{3}{ }^{+} \mathrm{TFA}-$ to the pristine $\mathrm{P}-\mathrm{X}$-ala-Boc is almost equal to the repeating unit molecular weight ratio of $\mathrm{P}-\mathrm{L}-\mathrm{ala}-\mathrm{NH}_{3}{ }^{+} \mathrm{TFA}^{-}$to P-X-ala-Boc.

Helical chirality induction of the polymers (typical procedure). Most of the helical chirality inductions in this work were carried out by the following steps: (1) The pre-prepared aqueous solutions of polymer and metal salt were mixed in certain volume ratio; (2) the as-obtained solution was diluted to a predetermined concentration (for measurements) by adding water and then allowed to stand still at $20^{\circ} \mathrm{C}$ for over $24 \mathrm{~h}$. In step (1), the volume ratio was sometimes adjusted to control the molar ratio of metal ion to polymer repeating unit. In step (2), the addition of extra water was not necessary in some cases.

Polymerization of $\mathbf{M}-\mathbf{L}-\mathbf{a l a}-\mathbf{N H}_{2}$. In this work, we tried to polymerize M-L-ala- $\mathrm{NH}_{2}$ using $\left[\mathrm{Rh}(\mathrm{cod})_{2}\right]^{+} \mathrm{BF}_{4}^{-}$as catalyst in two media: (1) pure water; (2) water solution of $\mathrm{HCl}\left(\mathrm{HCl}\right.$ and $\mathrm{M}-\mathrm{L}-$ ala- $\mathrm{NH}_{2}$ were in equal molar amount). No 
matter which medium was used, the polymerization was simply performed as follows. A solution of M-L-ala- $\mathrm{NH}_{2}$ (dissolved in one of the media above, $0.5 \mathrm{~mol} \mathrm{~L}^{-1}$ ) that has been bubbled with $\mathrm{N}_{2}$ was injected into the reaction tube loaded with $\left[\mathrm{Rh}(\mathrm{cod})_{2}\right]^{+} \mathrm{BF}_{4}^{-}$ ( $1 \mathrm{~mol} \%$ of $\mathrm{M}-\mathrm{L}-\mathrm{ala}-\mathrm{NH}_{2}$ ) under $\mathrm{N}_{2}$ protection, and then the polymerization reaction was conducted under magnetic stirring at $30^{\circ} \mathrm{C}$ for $48 \mathrm{~h}$.

When pure water was used as medium, the resulting solution was concentrated under reduced pressure at room temperature to eliminate most water, and the concentrate was dissolved by a small amount of $\mathrm{MeOH}$ and then diluted by a large amount of $\mathrm{EA}(\mathrm{EA} / \mathrm{MeOH} \approx 20 / 1(\mathrm{v} / \mathrm{v}))$ to precipitate the product. Finally, a sticky red semi-solid (yield $=9.2 \%$ ) was collected by centrifugation and vacuum drying.

When the water solution of $\mathrm{HCl}$ was used as medium, the resulting solution was concentrated under reduced pressure at room temperature to eliminate most water and $\mathrm{HCl}$, and then diluted by large amount of EtOH and vigorously stirred with $\mathrm{K}_{2} \mathrm{CO}_{3}$ powder for 15 min to eliminate the residual $\mathrm{HCl}$ and deprotonate the amino groups. After filtering off the solids, the filtrate was concentrated and diluted with EA $(\mathrm{EA} / \mathrm{MeOH} \approx 20 / 1(\mathrm{v} / \mathrm{v}))$ to precipitate the product. Finally, a pale yellow powder (yield $=15.1 \%$ ) was collected by centrifugation and vacuum drying. 
FT-IR \& NMR Spectra of the Monomer (M-L-ala-Boc)

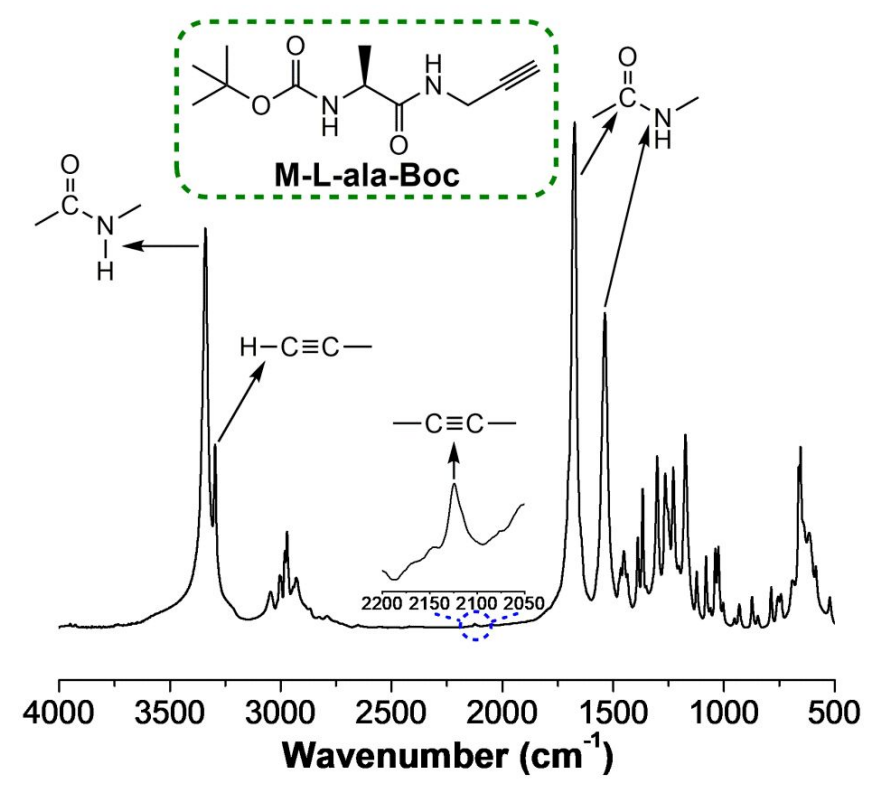

Figure S1. FT-IR spectrum (KBr tablet) of M-L-ala-Boc.
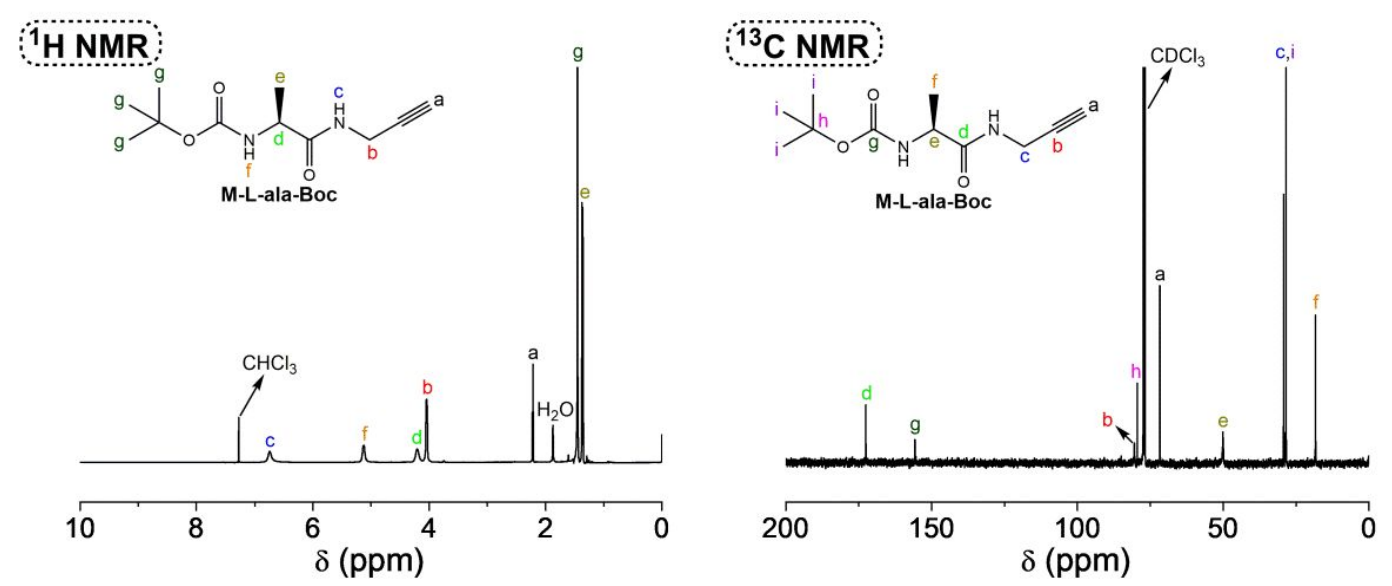

Figure S2. ${ }^{1} \mathrm{H}$ (400 MHz, 16 scans) and ${ }^{13} \mathrm{C}(100 \mathrm{MHz}, 1024$ scans) NMR spectra of $\mathrm{M}-\mathrm{L}-\mathrm{ala}-\mathrm{Boc}$ measured in $\mathrm{CDCl}_{3}$ at room temperature. 


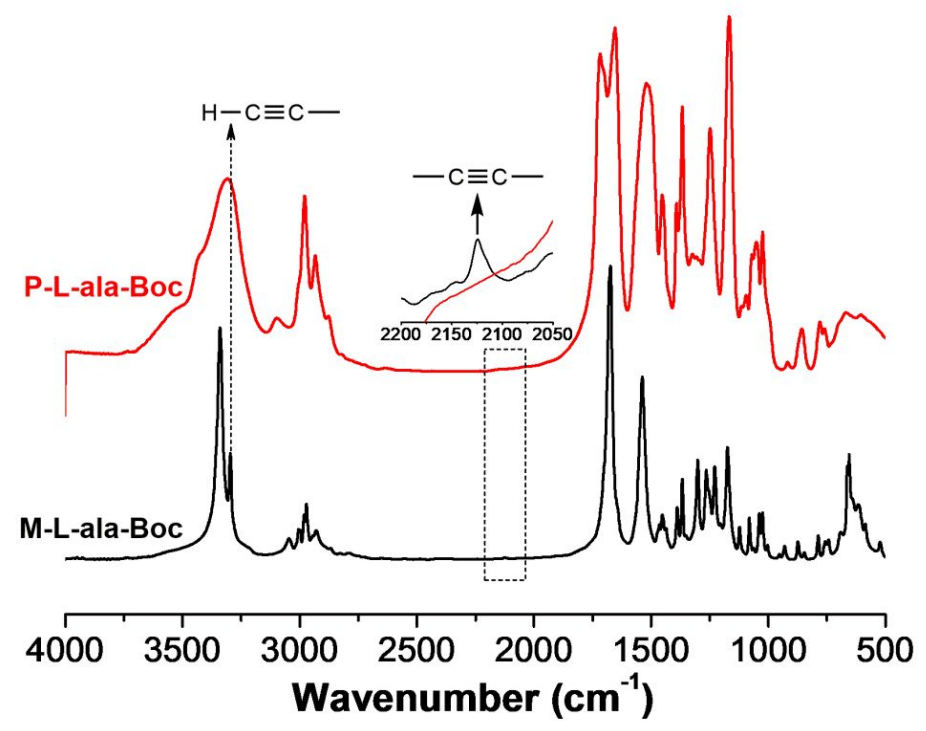

Figure S3. A comparison between the FT-IR spectra ( $\mathrm{KBr}$ tablet) of M-L-ala-Boc and P-L-ala-Boc.
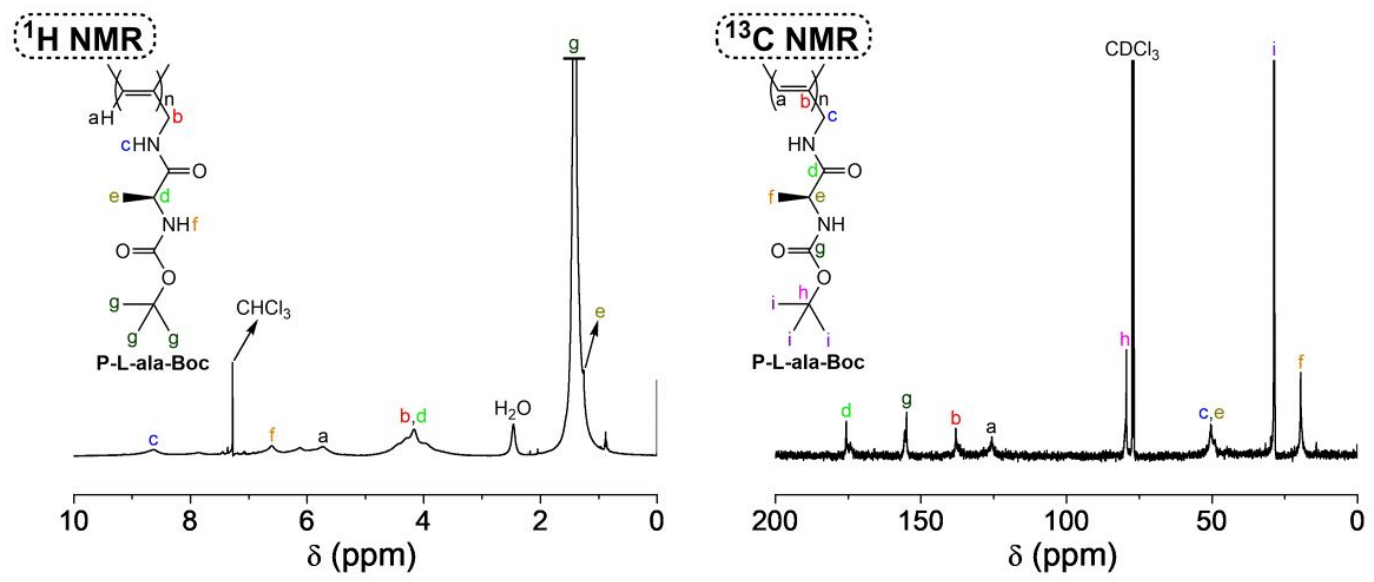

Figure S4. ${ }^{1} \mathrm{H}\left(400 \mathrm{MHz}, 16\right.$ scans) and ${ }^{13} \mathrm{C}(100 \mathrm{MHz}, 5000$ scans $)$ NMR spectra of P-L-ala-Boc measured in $\mathrm{CDCl}_{3}$ at room temperature. 


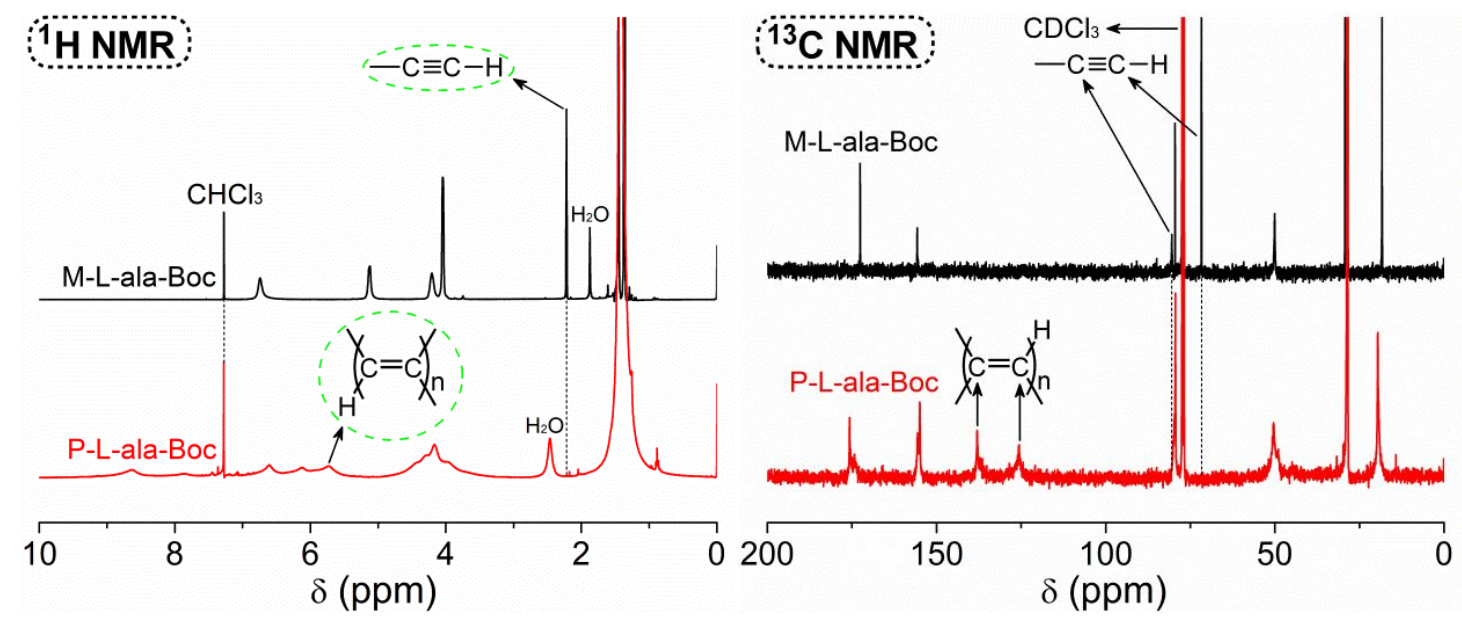

Figure S5. A comparison between the NMR spectra of M-L-ala-Boc and P-L-ala-Boc.

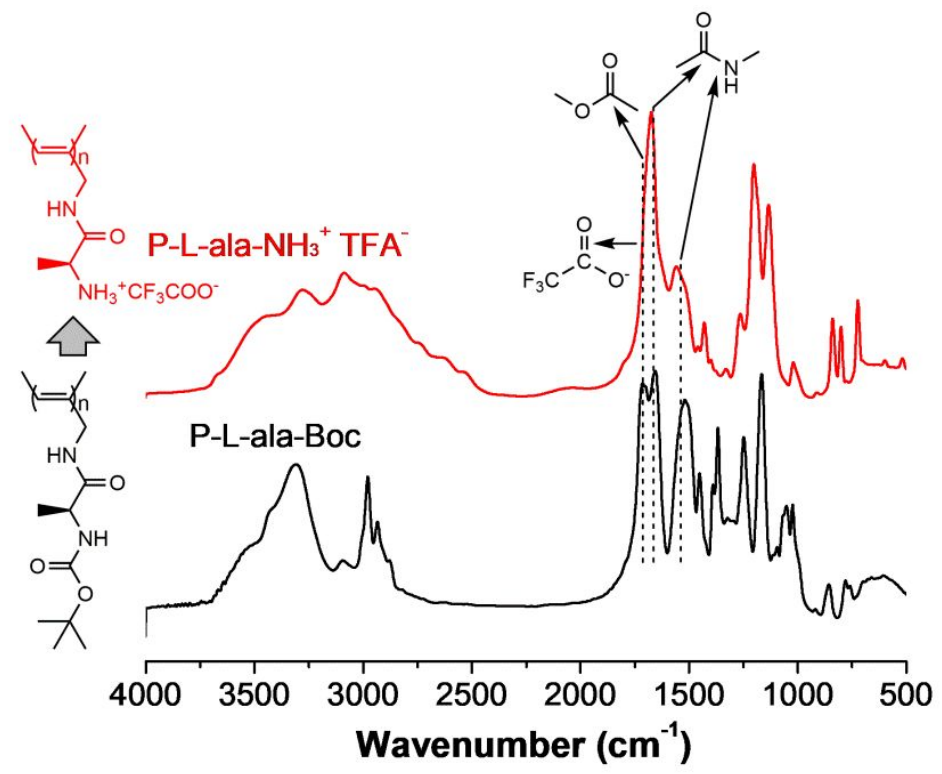

Figure S6. A comparison between the FT-IR spectra ( $\mathrm{KBr}$ tablet) of P-L-ala-Boc and P-L-ala- $\mathrm{NH}_{3}{ }^{+} \mathrm{TFA}^{-}$. 

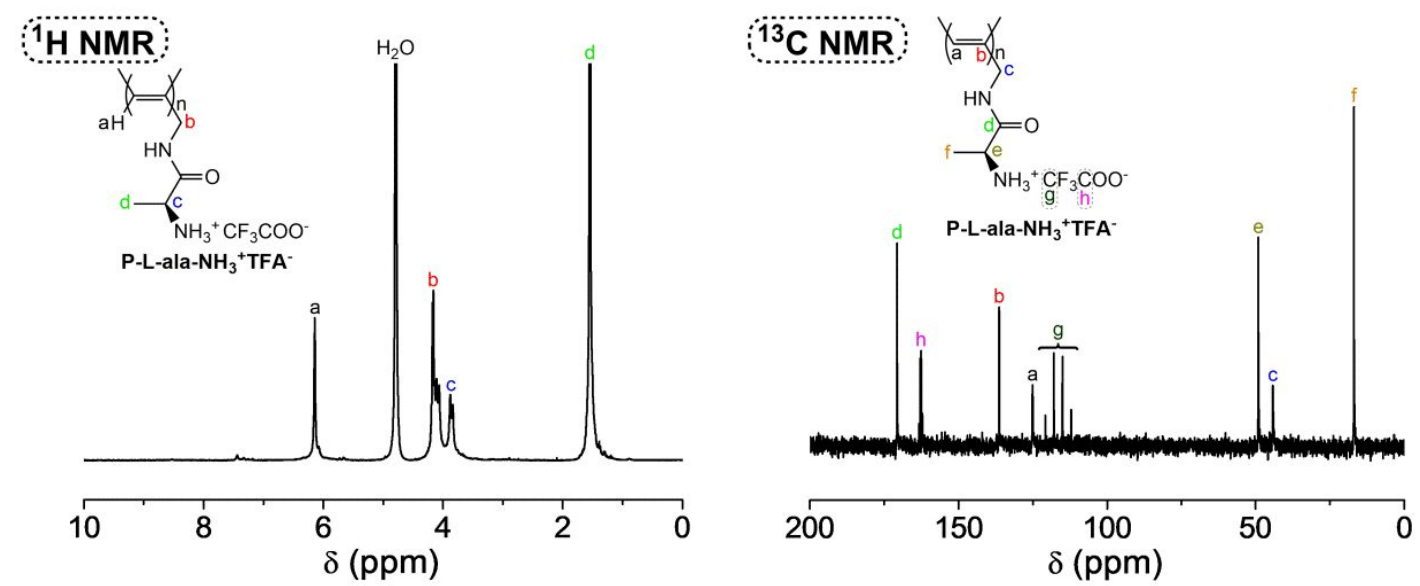

Figure S7. ${ }^{1} \mathrm{H}(400 \mathrm{MHz}, 16$ scans $)$ and ${ }^{13} \mathrm{C}(100 \mathrm{MHz}, 5000$ scans $)$ NMR spectra of P-L-ala- $\mathrm{NH}_{3}{ }^{+} \mathrm{TFA}^{-}$measured in $\mathrm{D}_{2} \mathrm{O}$ at room temperature. ${ }^{5}$

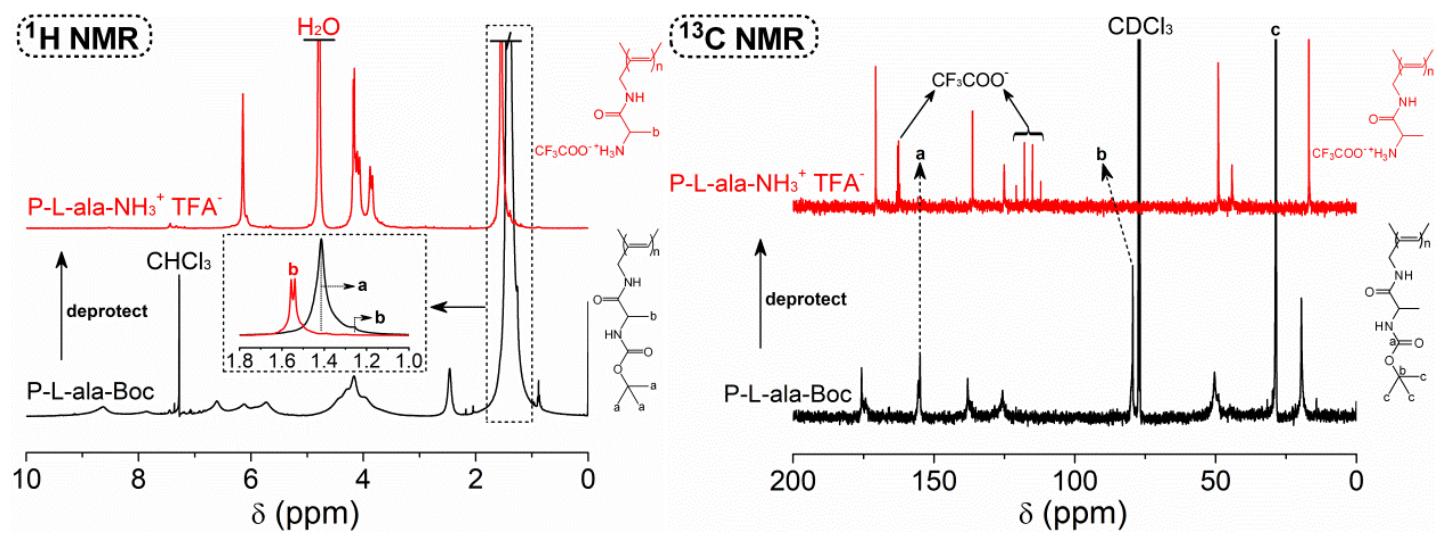

Figure S8. A comparison between the NMR spectra of P-L-ala-Boc and P-L-ala- $\mathrm{NH}_{3}{ }^{+} \mathrm{TFA}^{-}$. 


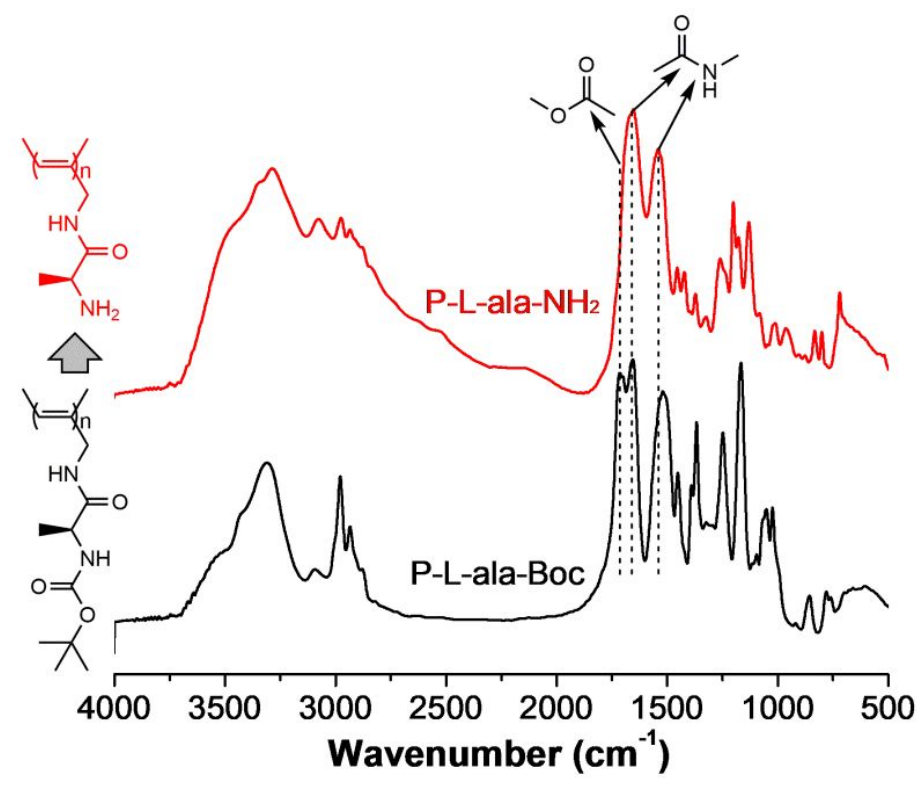

Figure S9. A comparison between the FT-IR spectra ( $\mathrm{KBr}$ tablet) of P-L-ala-Boc and P-L-ala- $\mathrm{NH}_{2}$.
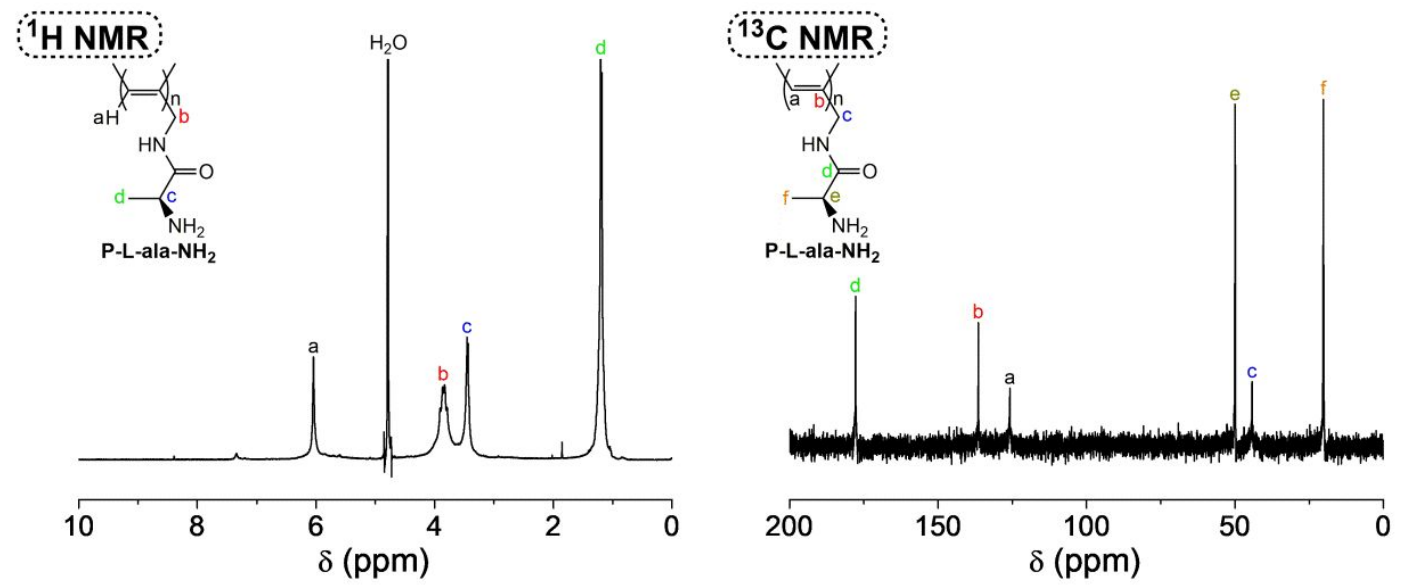

Figure S10. ${ }^{1} \mathrm{H}\left(400 \mathrm{MHz}, 16\right.$ scans) and ${ }^{13} \mathrm{C}$ (100 MHz, 5000 scans ) NMR spectra of P-L-ala- $\mathrm{NH}_{2}$ measured in $\mathrm{D}_{2} \mathrm{O}$ at room temperature. ${ }^{6}$ 


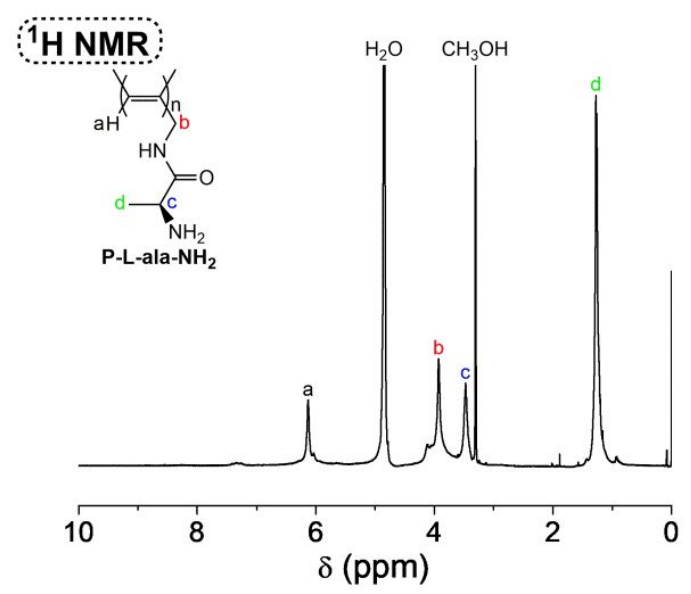

Figure S11. ${ }^{1} \mathrm{H}$ NMR spectra $\left(400 \mathrm{MHz}, 16\right.$ scans) of $\mathrm{P}-\mathrm{L}$-ala- $\mathrm{NH}_{2}$ measured in $\mathrm{CD}_{3} \mathrm{OD}$ at room temperature.
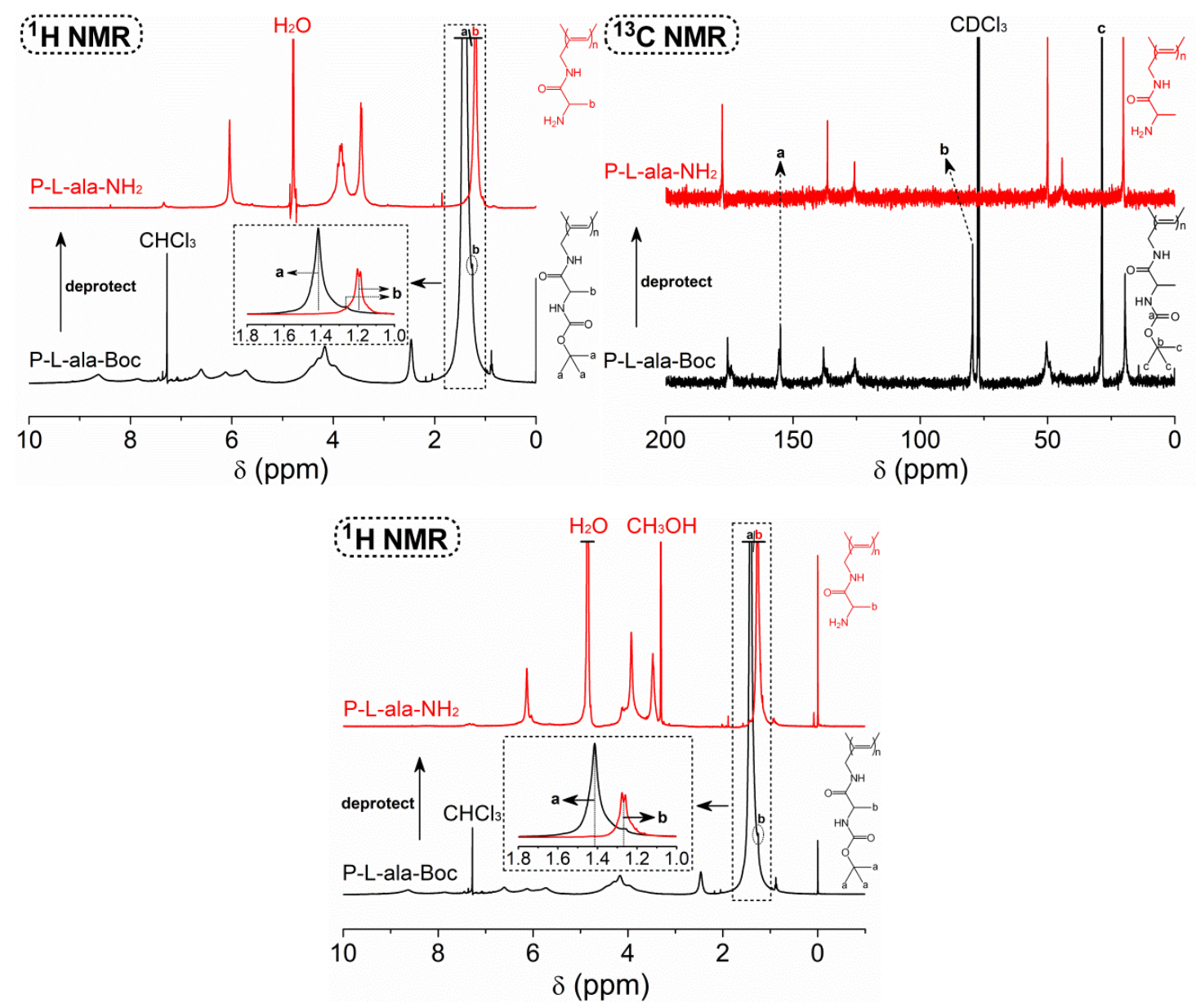

Figure S12. A comparison between the NMR spectra of P-L-ala-Boc and P-L-ala- $\mathrm{NH}_{2}$. 

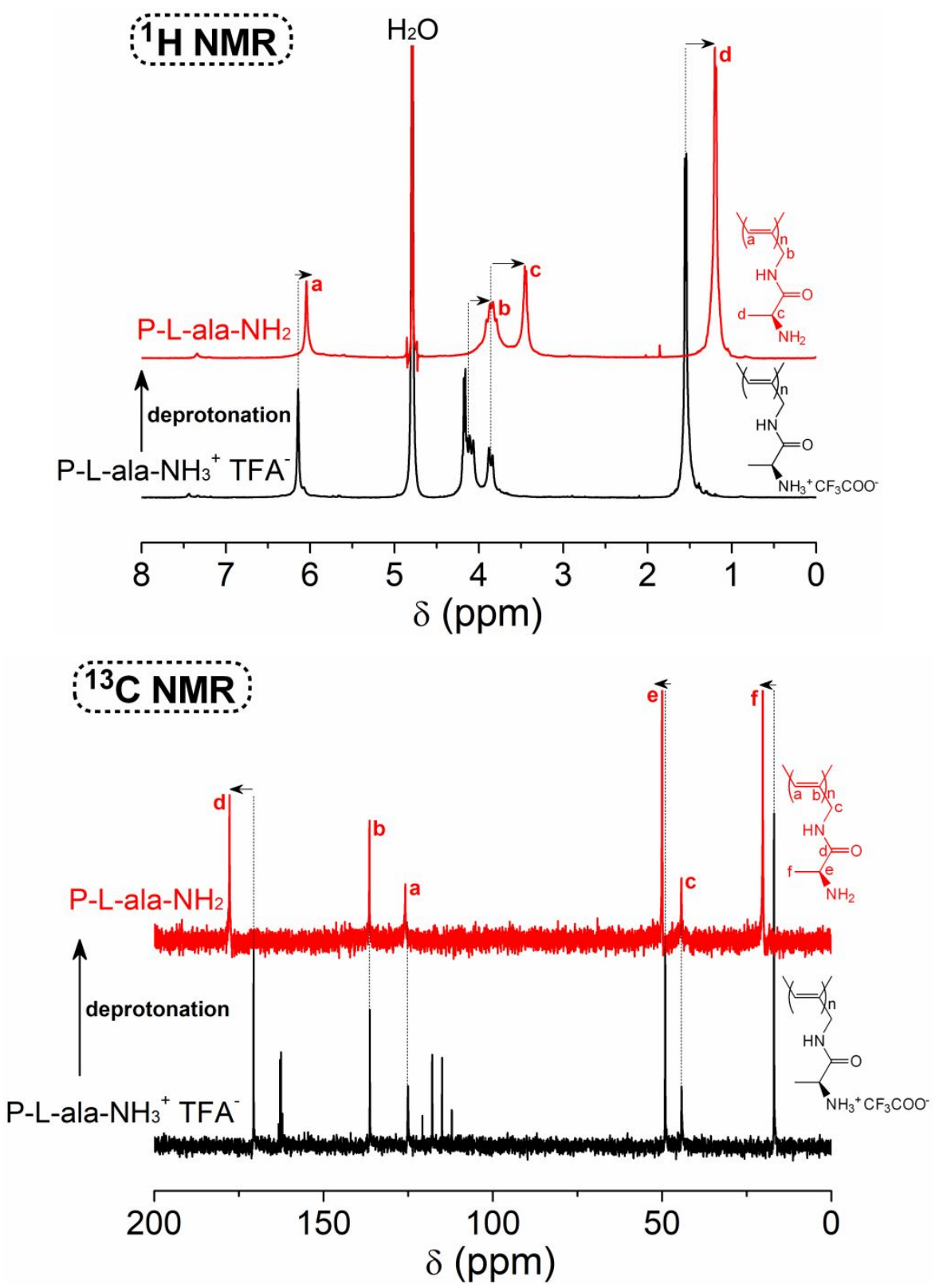

Figure S13. A comparison between the NMR spectra of $\mathrm{P}-\mathrm{L}-\mathrm{ala}-\mathrm{NH}_{3}{ }^{+} \mathrm{TFA}^{-}$and P-L-ala- $\mathrm{NH}_{2}{ }^{7}$ 


\section{GPC Curves of the Polymers}

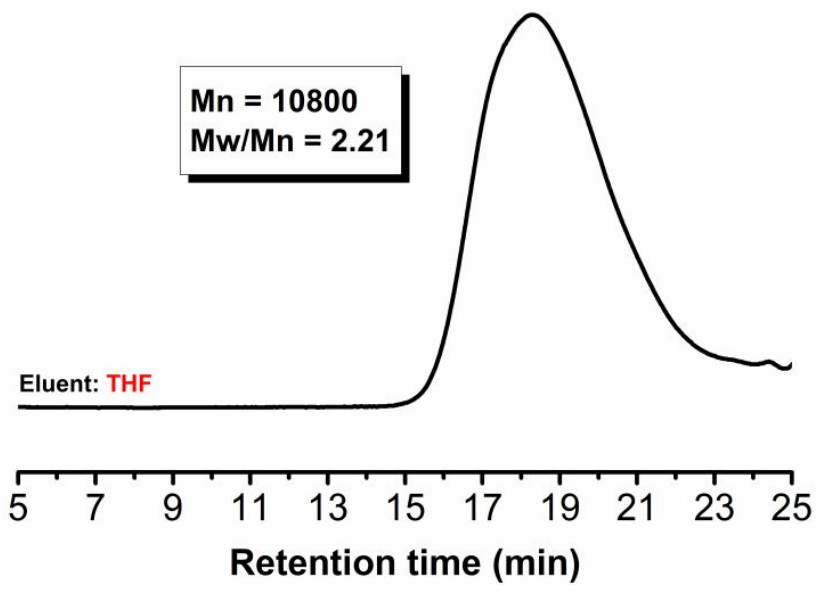

Figure S14. The GPC curve of P-L-ala-Boc.

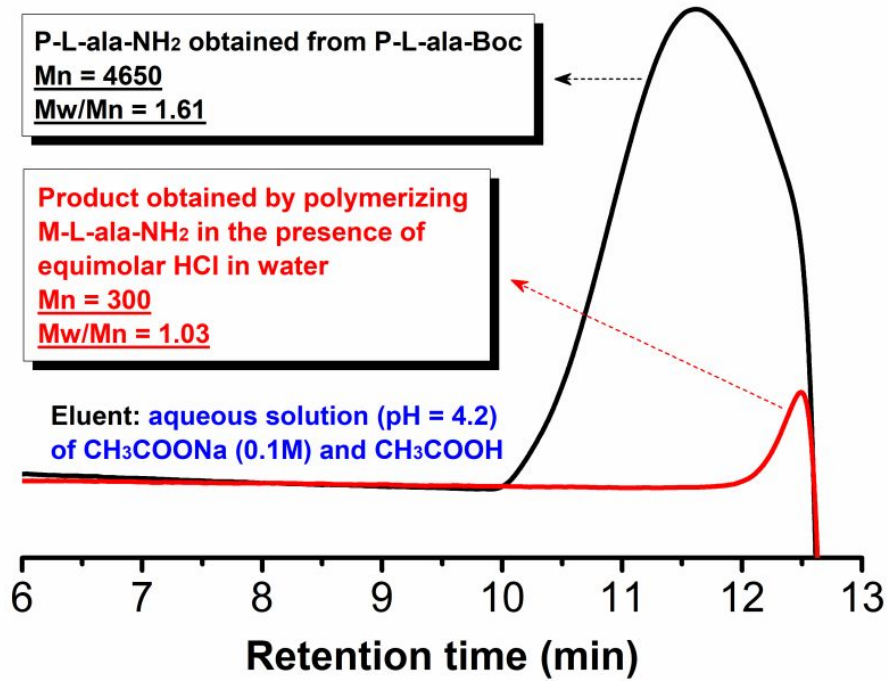

Figure S15. The GPC curves of P-L-ala- $\mathrm{NH}_{2}$ and the product obtained by polymerizing $\mathrm{M}-\mathrm{L}-\mathrm{ala}-\mathrm{NH}_{2}$ in the presence of equimolar $\mathrm{HCl}$ in water using $\left[\mathrm{Rh}(\operatorname{cod})_{2}\right]^{+} \mathrm{BF}_{4}^{-}$as catalyst. 


\section{Characterization of M-L-ala- $\mathrm{NH}_{2}$ and its "Polymerization" Products}
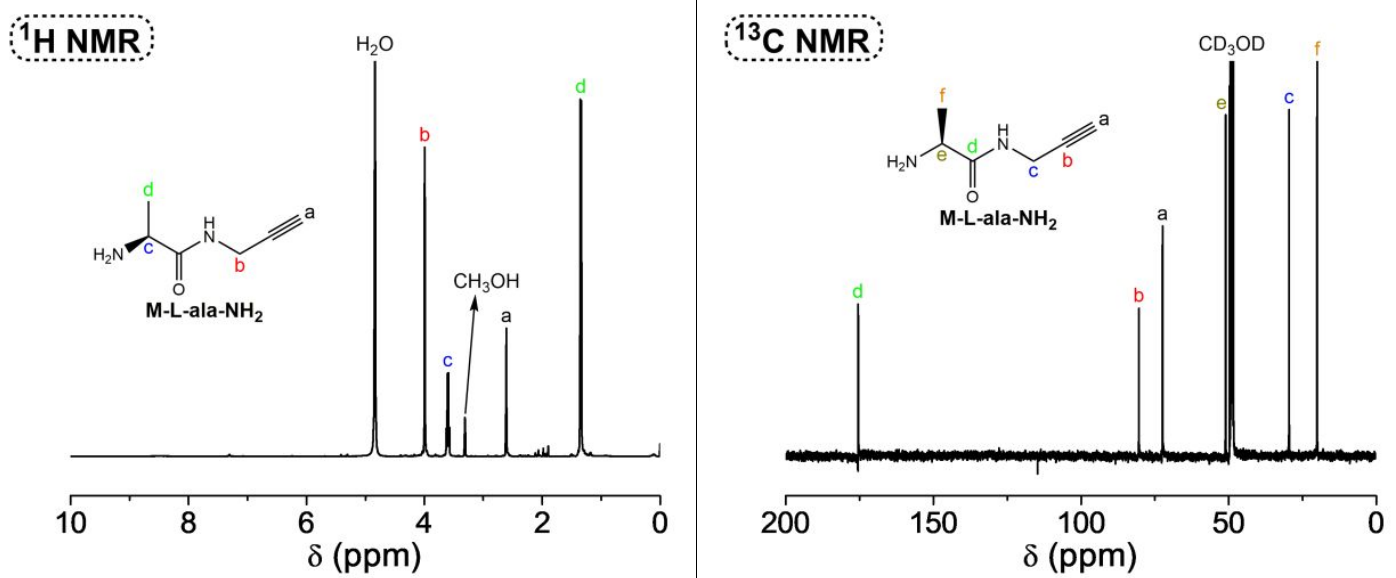

Figure S16. ${ }^{1} \mathrm{H}$ (400 MHz, 16 scans) and ${ }^{13} \mathrm{C}(100 \mathrm{MHz}, 1024$ scans) NMR spectra of M-L-ala- $\mathrm{NH}_{2}$ measured in $\mathrm{CD}_{3} \mathrm{OD}$ at room temperature.

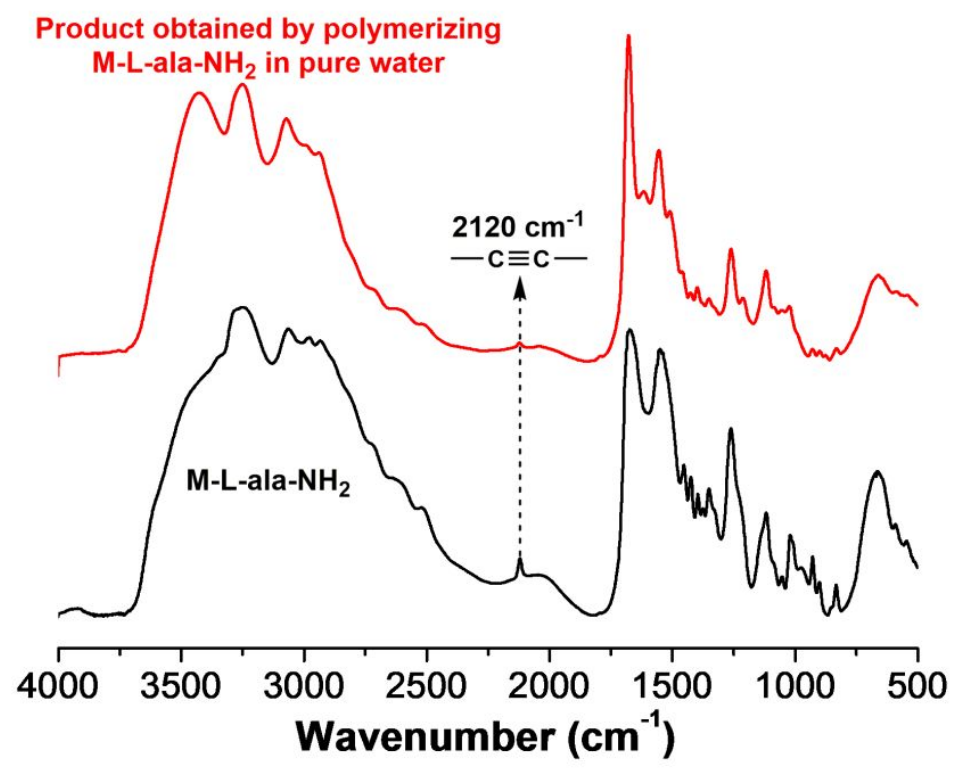

Figure S17. FT-IR spectra of M-L-ala- $\mathrm{NH}_{2}$ before and after polymerization in pure water. 


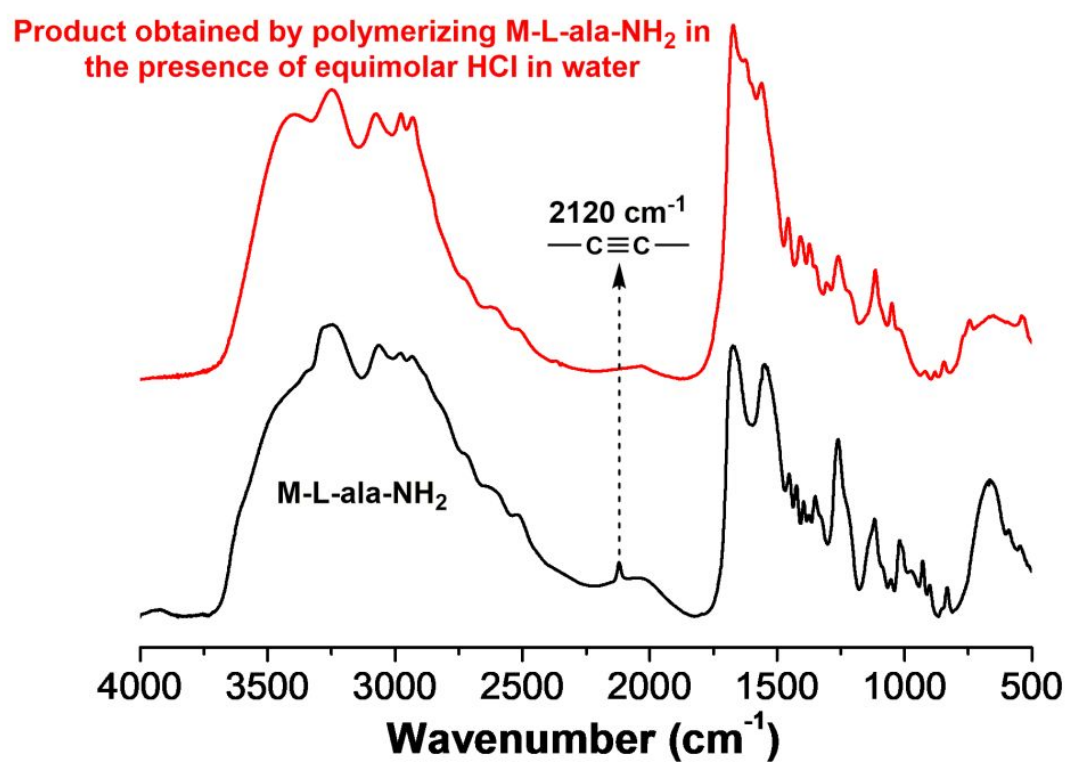

Figure S18. FT-IR spectra of M-L-ala- $\mathrm{NH}_{2}$ before and after polymerization in the water solution of $\mathrm{HCl}\left(\mathrm{HCl}\right.$ and $\mathrm{M}-\mathrm{L}-\mathrm{ala}-\mathrm{NH}_{2}$ were in equal molar amount).

\section{CD and UV-vis Absorption Spectra of the Polymers}

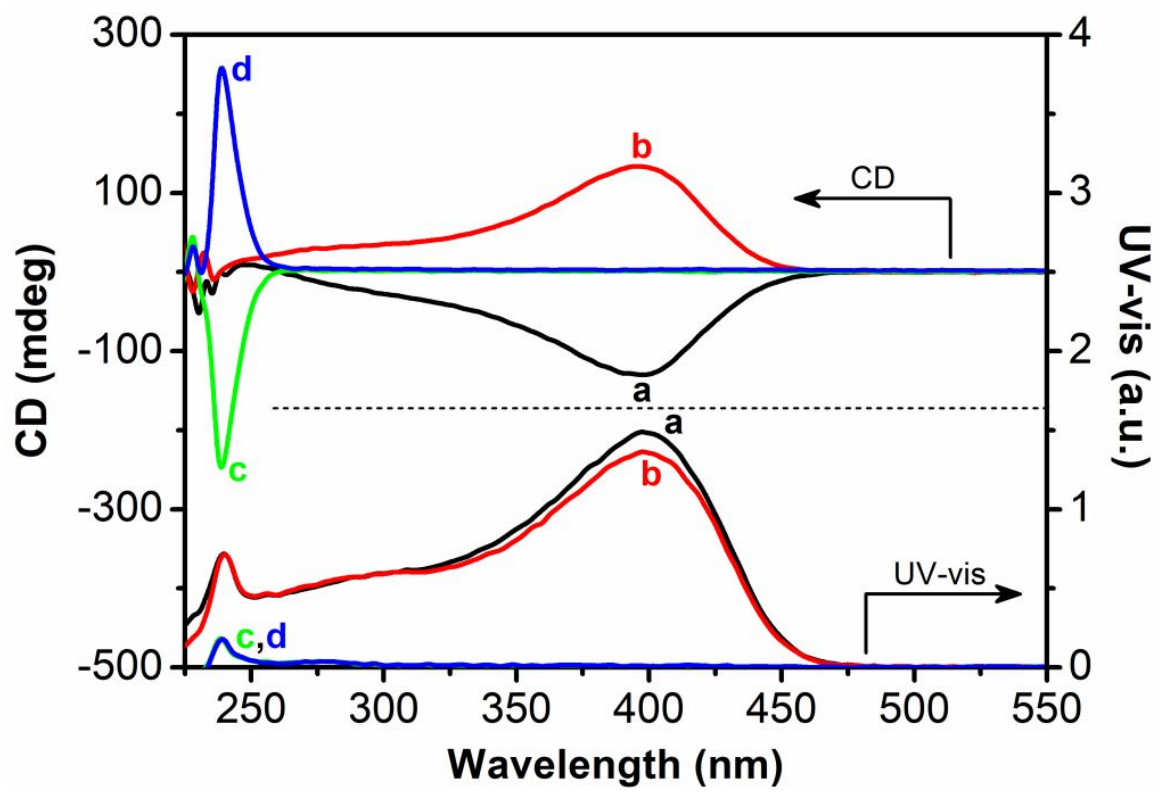

Figure S19. CD and UV-vis absorption spectra of P-L-ala-Boc (a), P-D-ala-Boc (b), M-L-ala-Boc (c), and M-D-ala-Boc (d) measured in TCM at $20^{\circ} \mathrm{C}$. Polymer (a and b) concentration $=5 \times 10^{-4} \mathrm{~mol} \mathrm{~L}^{-1}$; monomer $(\mathrm{c}$ and $\mathrm{d})$ concentration $=5 \times 10^{-3} \mathrm{~mol} \mathrm{~L}^{-1}$. 


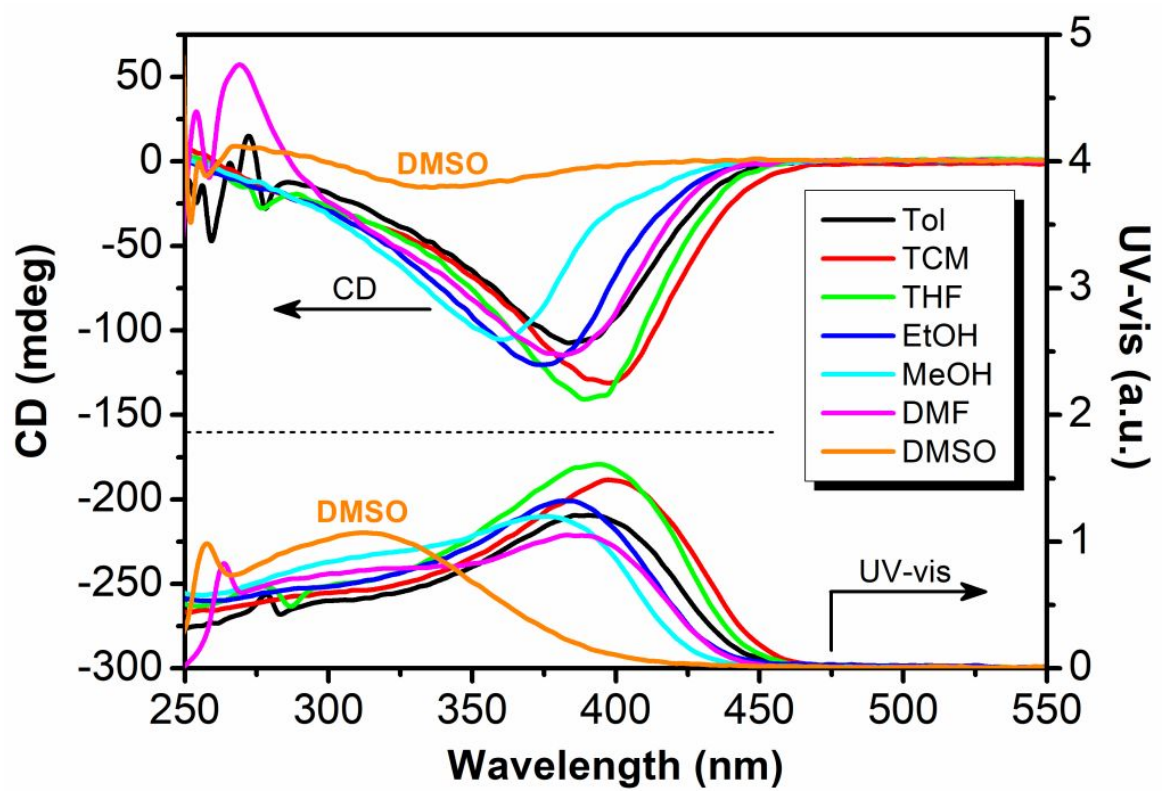

Figure S20. CD and UV-vis absorption spectra of P-L-ala-Boc measured in varied solvents $\left(5 \times 10^{-4} \mathrm{~mol} \mathrm{~L}^{-1}\right)$ at $20^{\circ} \mathrm{C}$. The polymer was dissolved in Tol, TCM, THF, DMF, and DMSO, but dispersed in $\mathrm{EtOH}$ and $\mathrm{MeOH}$.

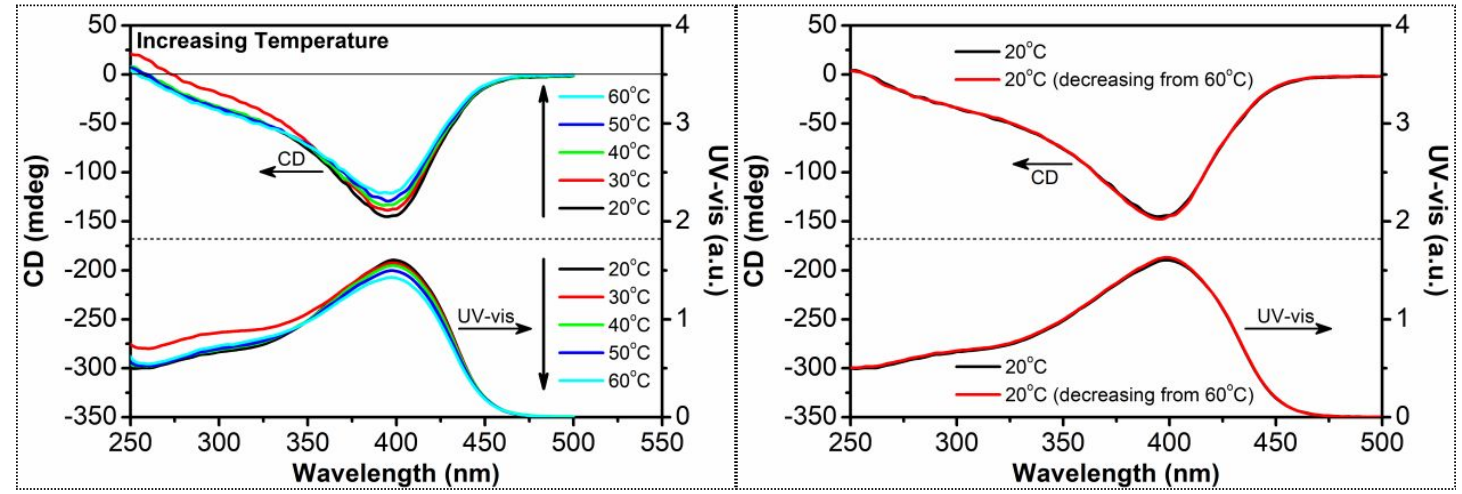

Figure S21. CD and UV-vis absorption spectra of P-L-ala-Boc measured in TCM $\left(5 \times 10^{-4} \mathrm{~mol} \mathrm{~L}^{-1}\right)$ at varied temperature. 

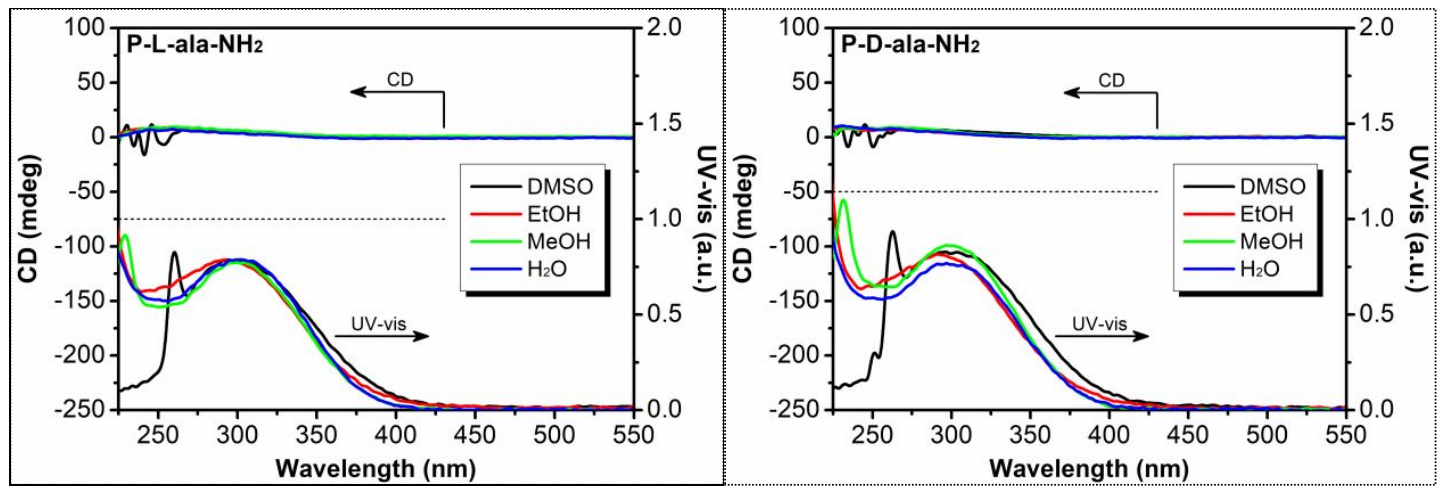

Figure S22. $\mathrm{CD}$ and UV-vis absorption spectra of P-L-ala- $\mathrm{NH}_{2}$ and $\mathrm{P}-\mathrm{D}-\mathrm{ala}-\mathrm{NH}_{2}$ measured in varied solvents $\left(5 \times 10^{-4} \mathrm{~mol} \mathrm{~L}^{-1}\right)$ at $20{ }^{\circ} \mathrm{C}$. The polymer was completely dissolved in all the solvents.

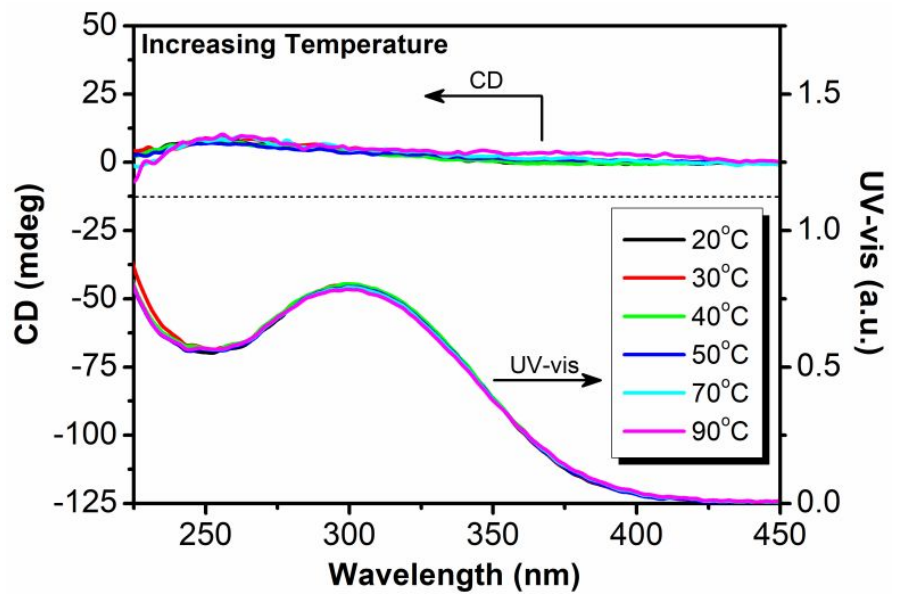

Figure S23. CD and UV-vis absorption spectra of P-L-ala- $\mathrm{NH}_{2}$ measured in $\mathrm{H}_{2} \mathrm{O}$ $\left(5 \times 10^{-4} \mathrm{~mol} \mathrm{~L}^{-1}\right)$ at varied temperature.

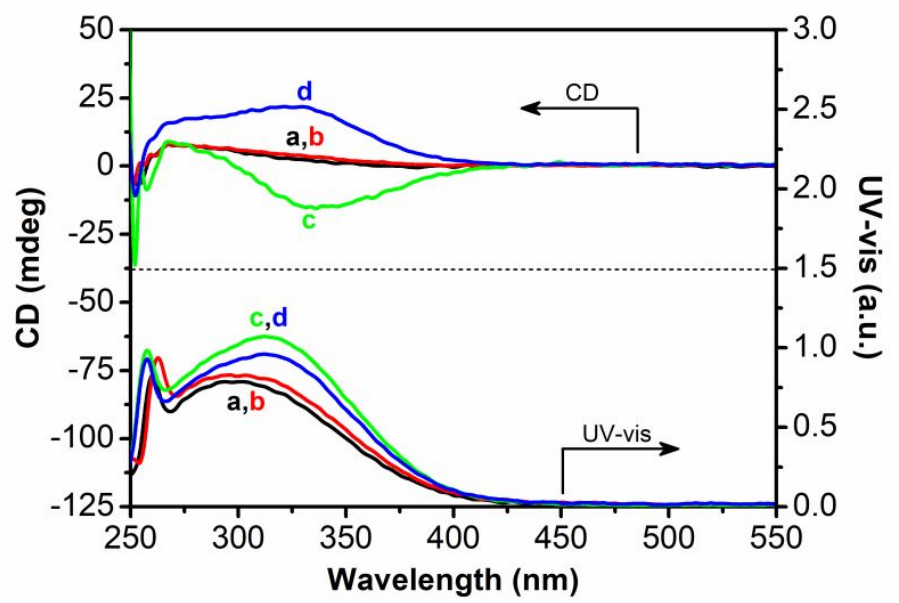

Figure S24. CD and UV-vis absorption spectra of P-L-ala- $\mathrm{NH}_{2}$ (a), P-D-ala- $\mathrm{NH}_{2}$ (b), P-L-ala-Boc (c), and P-D-ala-Boc (d) measured in DMSO $\left(5 \times 10^{-4} \mathrm{~mol} \mathrm{~L}^{-1}\right)$ at $20^{\circ} \mathrm{C}$. 
CD and UV-vis Absorption Spectra of the Metal Chlorides

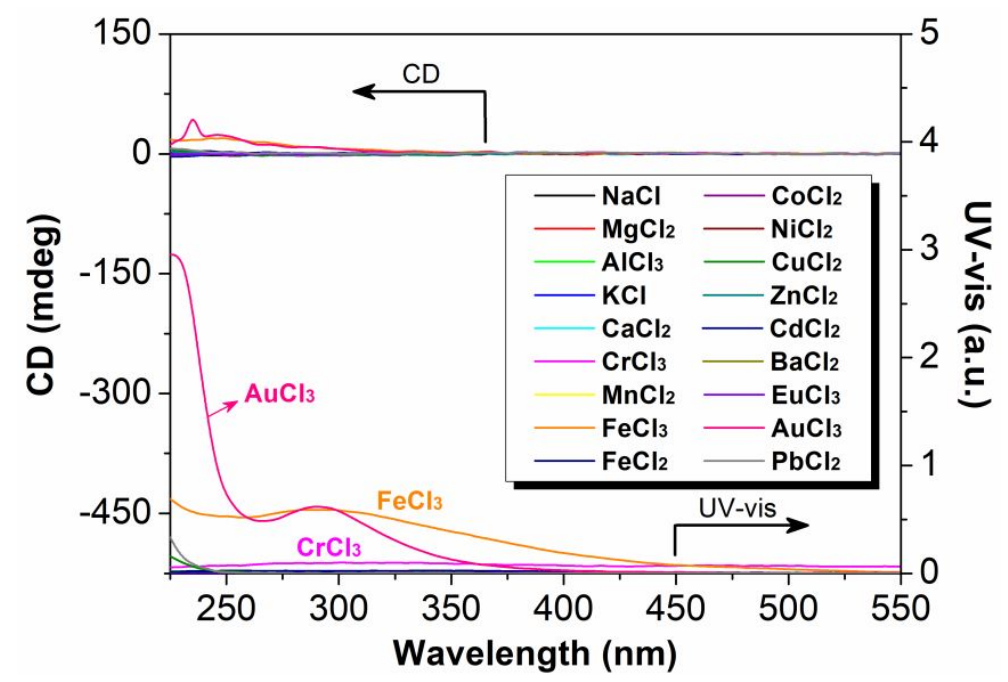

Figure S25. CD and UV-vis absorption spectra of the metal chlorides measured in water at $20^{\circ} \mathrm{C}$. The concentration of $\mathrm{FeCl}_{3}, \mathrm{FeCl}_{2}$, and $\mathrm{AuCl}_{3}$ was $2.5 \times 10^{-4} \mathrm{~mol} \mathrm{~L}^{-1}$, and the concentration of other metal chlorides was $5 \times 10^{-4} \mathrm{~mol} \mathrm{~L}^{-1}$.

\section{DLS and GPC Analysis of the Helical Chirality Induction Process}

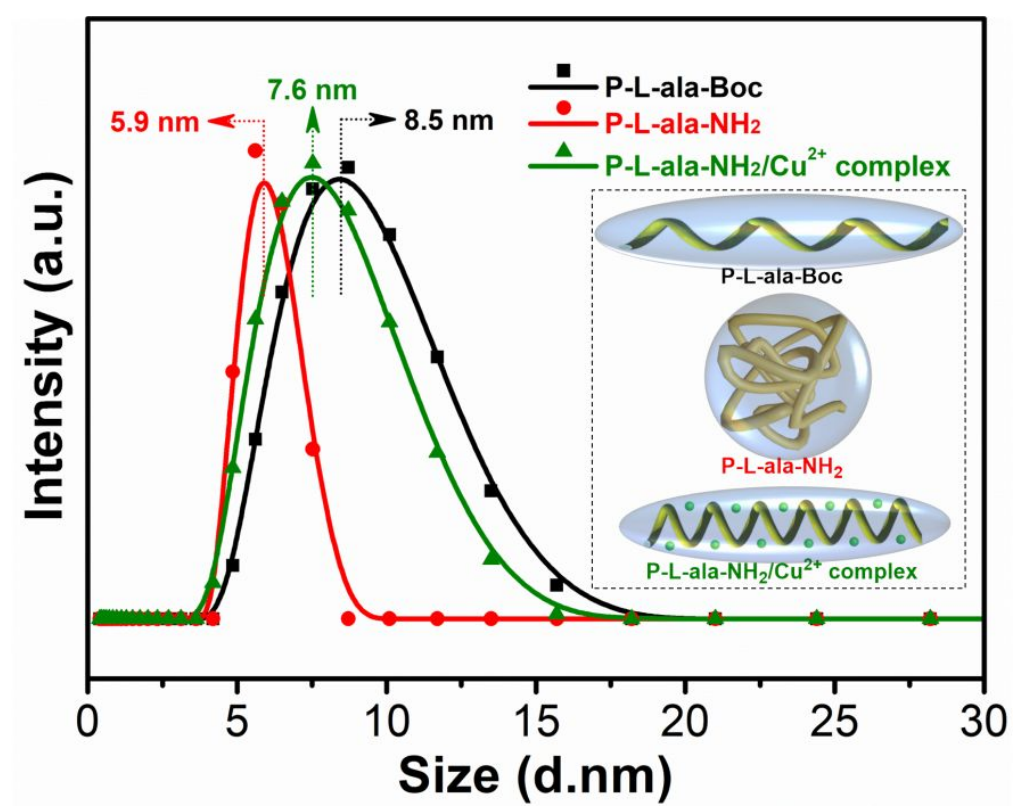

Figure S26. DLS curves of P-L-ala-Boc (in TCM), P-L-ala- $\mathrm{NH}_{2}$ (in water), and P-L-ala- $\mathrm{NH}_{2} / \mathrm{Cu}^{2+}$ complex (in water). The concentration was $10^{-2} \mathrm{~mol} \mathrm{~L}^{-1}$ for all the polymers. 


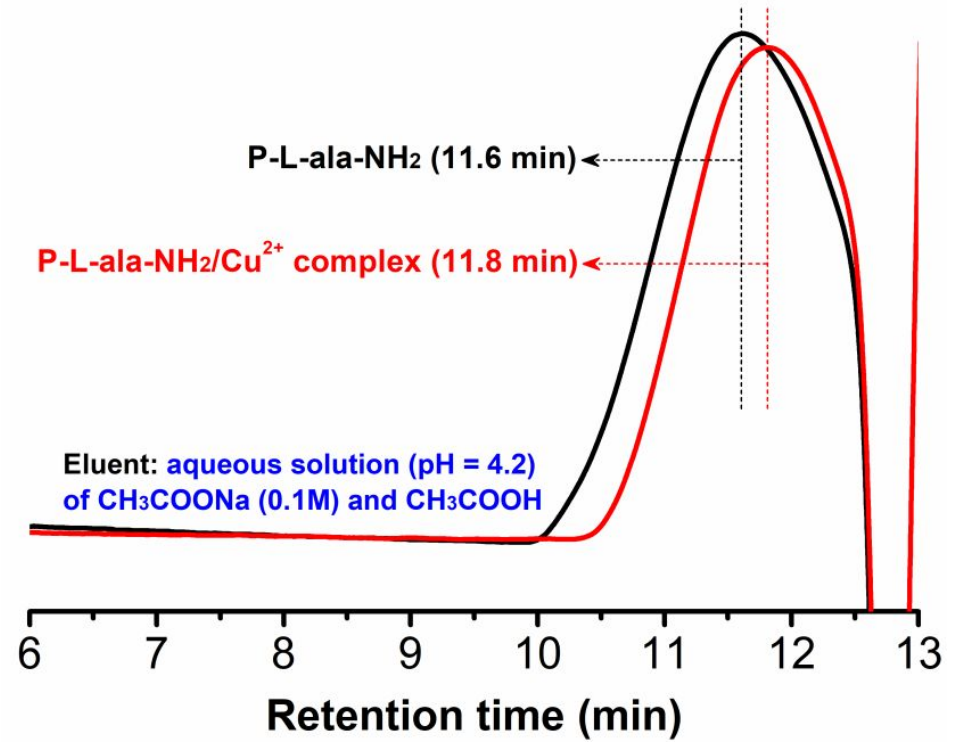

Figure S27. GPC curves of P-L-ala- $\mathrm{NH}_{2}$ and $\mathrm{P}-\mathrm{L}-\mathrm{ala}-\mathrm{NH}_{2} / \mathrm{Cu}^{2+}$ complex.

\section{Conformation Tracing of $\mathrm{P}-\mathrm{L}-\mathrm{ala}-\mathrm{NH}_{2}$ after Mixing with $\mathrm{CuCl}_{2}$}
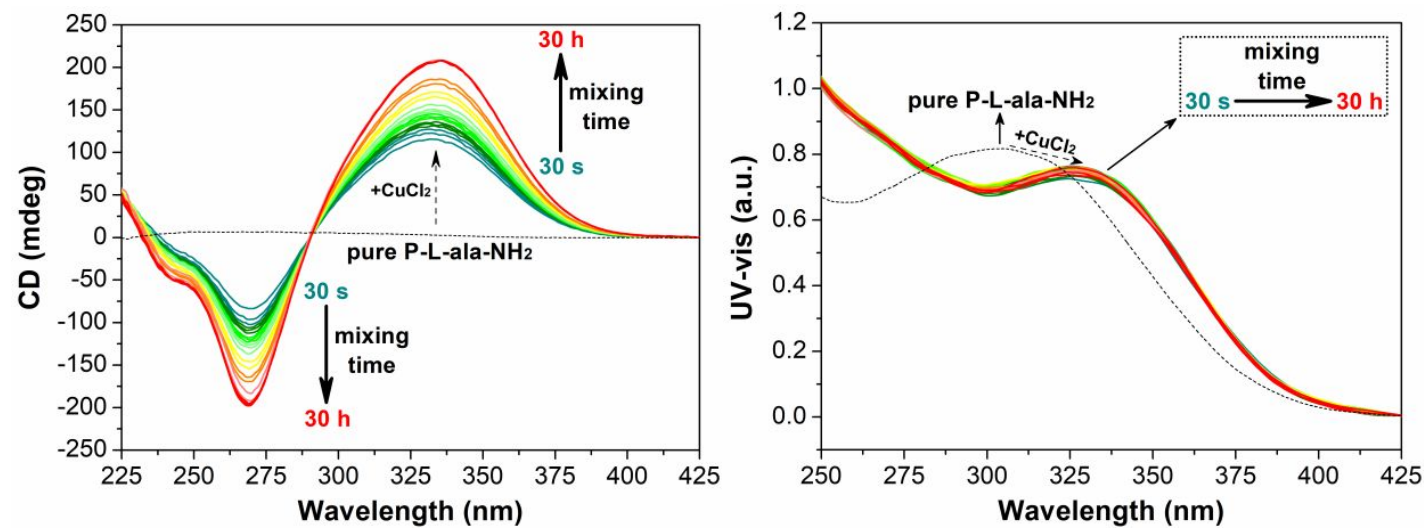

Figure S28. The time-dependent $\mathrm{CD}$ and UV-vis absorption spectra of P-L-ala- $\mathrm{NH}_{2}$ $\left(5 \times 10^{-4} \mathrm{~mol} \mathrm{~L}^{-1}\right)$ after mixing with equimolar (by monomer unit) $\mathrm{CuCl}_{2}$. 


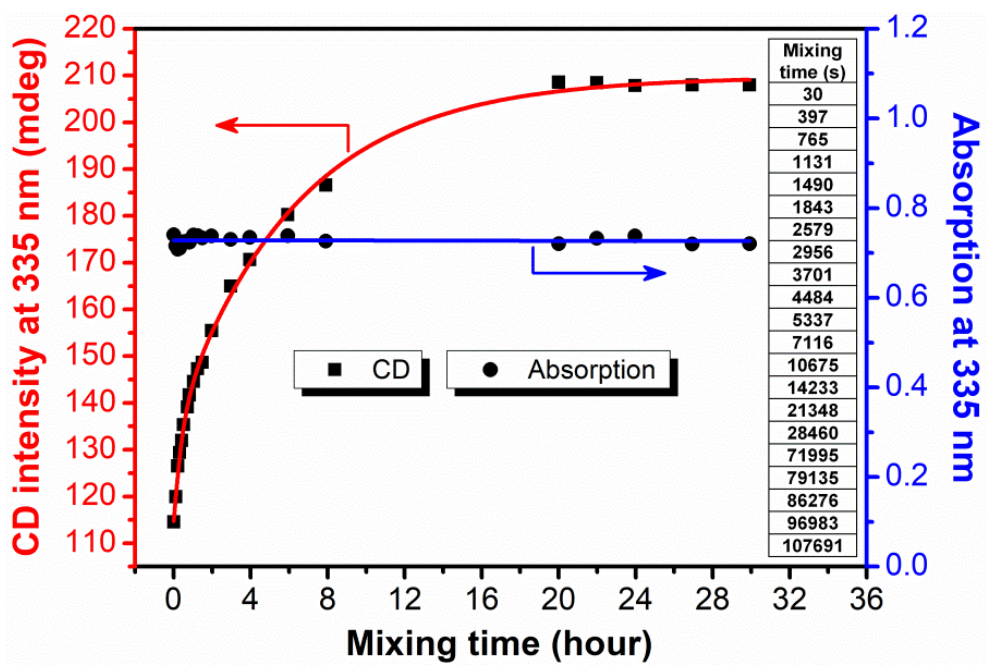

Figure S29. The plots of $\mathrm{CD}$ and UV-vis absorption intensity at $335 \mathrm{~nm}$ of the P-L-ala- $\mathrm{NH}_{2}$ and $\mathrm{CuCl}_{2}$ mixture as a function of mixing time.

Thermal Stability of the Induced Helical Structure in P-L-ala- $\mathrm{NH}_{2} / \mathrm{Cu}^{2+}$

\section{Complex}

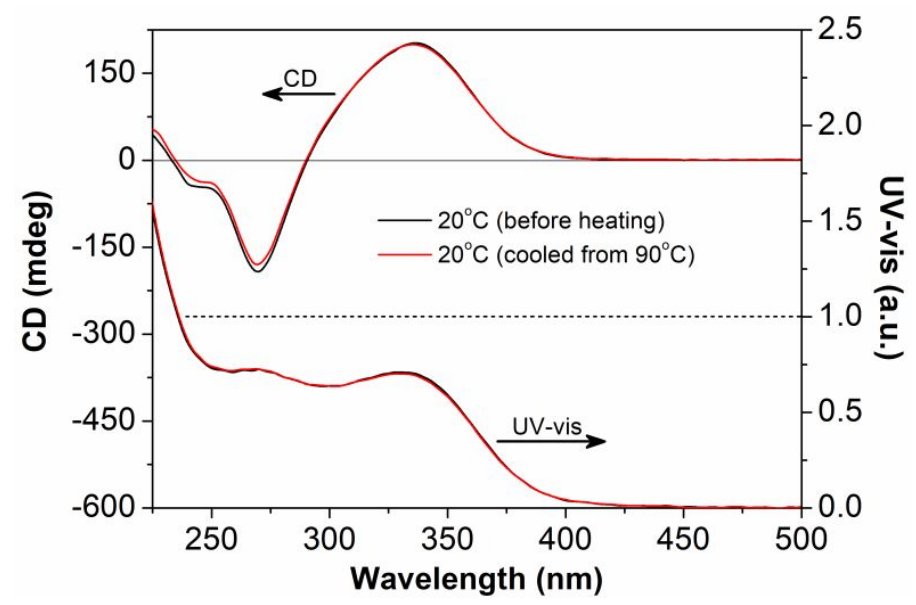

Figure S30. $\mathrm{CD}$ and $\mathrm{UV}$-vis absorption spectra of $\mathrm{P}-\mathrm{L}$-ala- $\mathrm{NH}_{2}$ and $\mathrm{CuCl}_{2}$ equimolar (by monomer unit) mixture in water before and after the thermal treatment_- heating from $20^{\circ} \mathrm{C}$ to $90^{\circ} \mathrm{C}$ and then cooling to $20^{\circ} \mathrm{C}$. 


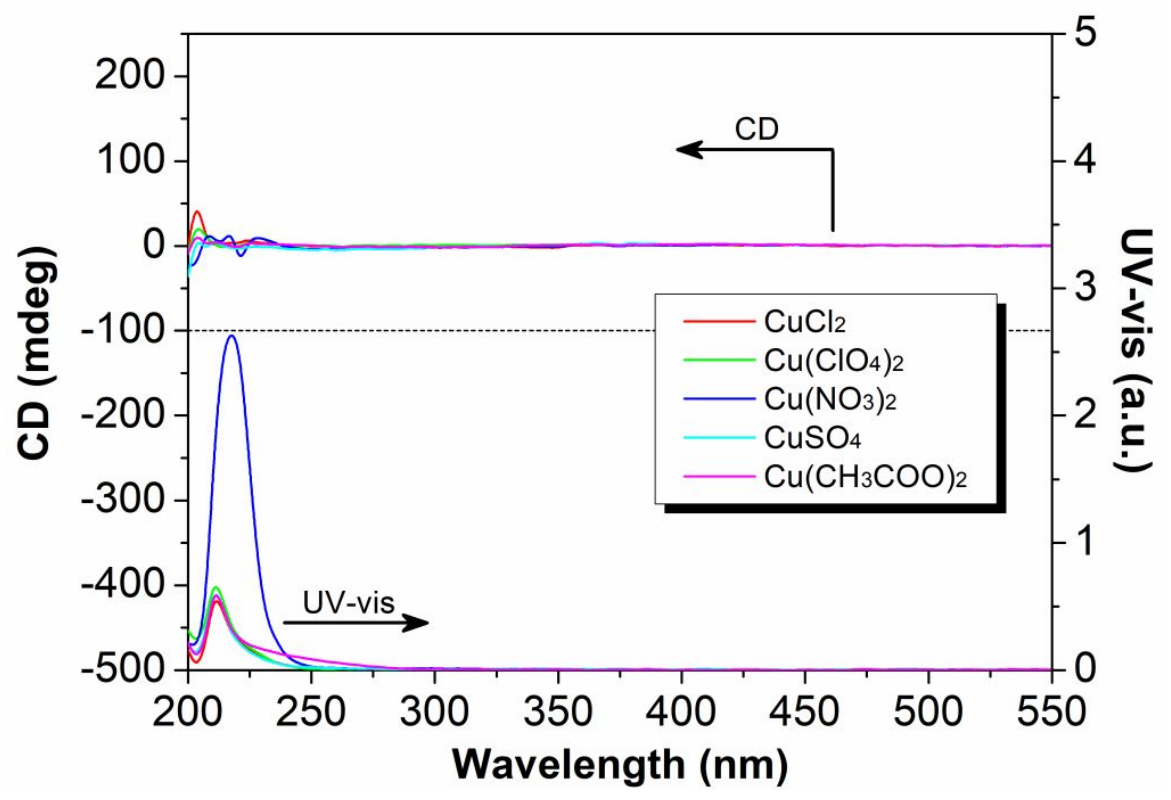

Figure S31. CD and UV-vis absorption spectra of the copper ( II ) salts $\left(5 \times 10^{-4} \mathrm{~mol}\right.$ $\mathrm{L}^{-1}$ ) in water at $20^{\circ} \mathrm{C}$.

\section{Structural Characterization of $\mathrm{P}-\mathrm{L}=\mathrm{D}-\mathrm{ala}-\mathrm{NH}_{2}$}

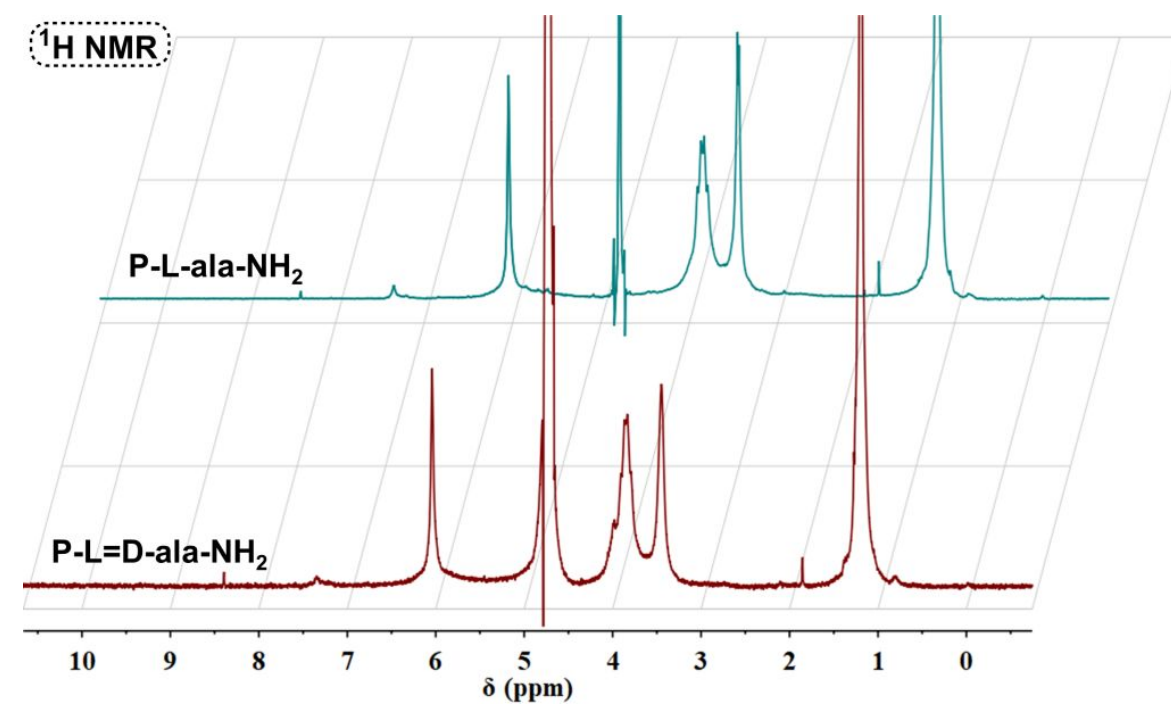

Figure S32. A comparison between the ${ }^{1} \mathrm{H}$ NMR spectra of P-L-ala- $\mathrm{NH}_{2}$ and $\mathrm{P}-\mathrm{L}=\mathrm{D}-\mathrm{ala}-\mathrm{NH}_{2} \cdot{ }^{8}$ 


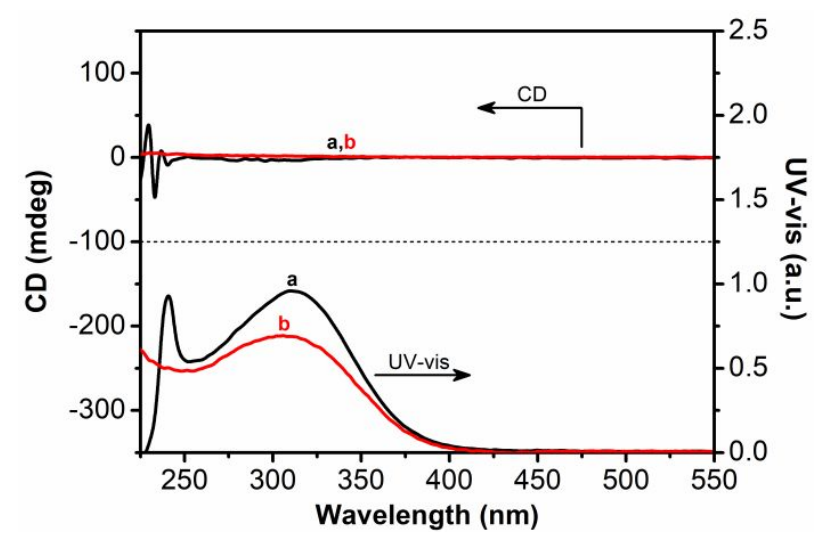

Figure S33. CD and UV-vis absorption spectra of $\mathrm{P}-\mathrm{L}=\mathrm{D}-\mathrm{ala}-\mathrm{Boc}(\mathrm{a}$, in TCM) and $\mathrm{P}-\mathrm{L}=\mathrm{D}-\mathrm{ala}-\mathrm{NH}_{2}\left(\mathrm{~b}\right.$, in $\left.\mathrm{H}_{2} \mathrm{O}\right)$ measured at $20^{\circ} \mathrm{C}\left(5 \times 10^{-4} \mathrm{~mol} \mathrm{~L}^{-1}\right.$ by monomer unit).

\section{Specific Rotations of Some Important Samples Prepared in This Work}

Table S1. Specific rotations of some important samples prepared in this work. ${ }^{\text {a }}$

\begin{tabular}{|c|c|c|c|}
\hline Sample Name & {$[\alpha]_{\mathrm{D}}^{25}$} & Solvent & $\begin{array}{l}\text { Test Concentration } \\
(\mathrm{g} / 100 \mathrm{~mL})\end{array}$ \\
\hline M-L-ala-Boc & -34.7 & TCM & 1 \\
\hline M-D-ala-Boc & +35.0 & TCM & 1 \\
\hline P-L-ala-Boc & -1100 & TCM & 0.1 \\
\hline P-D-ala-Boc & +1106 & TCM & 0.1 \\
\hline P-L-ala- $\mathrm{NH}_{2}$ & -2.9 & $\mathrm{H}_{2} \mathrm{O}$ & 1 \\
\hline P-D-ala-NH ${ }_{2}$ & +3.0 & $\mathrm{H}_{2} \mathrm{O}$ & 1 \\
\hline $\begin{array}{c}\text { Mixture of } \\
\text { P-L-ala- } \mathrm{NH}_{2} \& \\
\mathrm{CuCl}_{2} \cdot 2 \mathrm{H}_{2} \mathrm{O}^{\mathrm{b}}\end{array}$ & $+1134^{\mathrm{c}}$ & $\mathrm{H}_{2} \mathrm{O}$ & $0.1^{\mathrm{d}}$ \\
\hline $\begin{array}{c}\text { Mixture of } \\
\text { P-D-ala- } \mathrm{NH}_{2} \& \\
\mathrm{CuCl}_{2} \cdot 2 \mathrm{H}_{2} \mathrm{O}^{\mathrm{b}}\end{array}$ & $-1174^{\mathrm{c}}$ & $\mathrm{H}_{2} \mathrm{O}$ & $0.1^{\mathrm{d}}$ \\
\hline $\begin{array}{c}\text { Mixture of } \\
\text { P-L-ala- } \mathrm{NH}_{2} \& \\
\mathrm{Ag}_{2} \mathrm{SO}_{4}^{\mathrm{b}}\end{array}$ & $+139^{c}$ & $\mathrm{H}_{2} \mathrm{O}$ & $0.1^{\mathrm{d}}$ \\
\hline $\begin{array}{c}\text { Mixture of } \\
\text { P-D-ala- } \mathrm{NH}_{2} \& \\
\mathrm{Ag}_{2} \mathrm{SO}_{4}^{\mathrm{b}}\end{array}$ & $-144^{c}$ & $\mathrm{H}_{2} \mathrm{O}$ & $0.1^{\mathrm{d}}$ \\
\hline
\end{tabular}

aAll the samples were measured at $25^{\circ} \mathrm{C}$ in a 1 decimeter polarimeter tube with a JASCO P-2000 digital polarimeter (sodium D-line, $589 \mathrm{~nm}$ ).

${ }^{b}$ The monomer unit and metal salt were equal in molar amount. The mixed solution has been stored at $25^{\circ} \mathrm{C}$ for more than 24 hours before the measurement.

${ }^{\mathrm{c}}$ calculated based on the mass of polymer ${ }^{\mathrm{d}}$ concentration of polymer 
Thermal Stability of the Induced Helical Structure in P-L-ala- $\mathrm{NH}_{2} / \mathrm{Ag}^{+} \mathrm{Complex}$
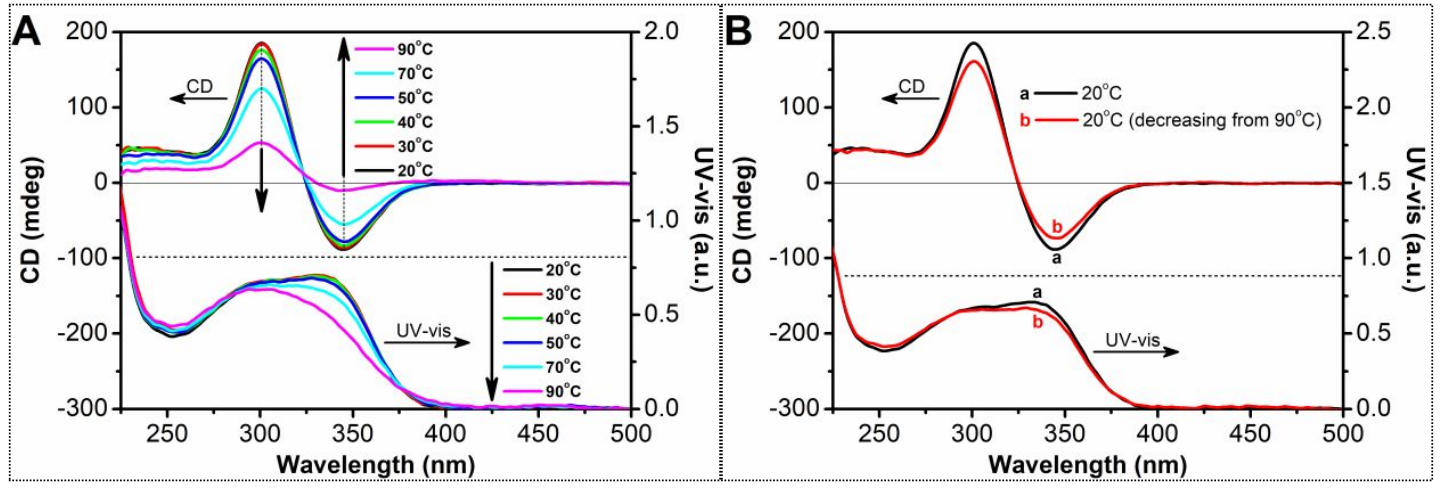

Figure S34. $\mathrm{CD}$ and UV-vis absorption spectra of P-L-ala- $\mathrm{NH}_{2}$ and $\mathrm{Ag}_{2} \mathrm{SO}_{4}$ equimolar (by monomer unit) mixture in water measured during heating (A) and after cooling (B).

CD, UV-vis Absorption, and NMR Spectra of the P-L-ala- $\mathrm{NH}_{2}$ and $\mathrm{CuCl}_{2}$ Mixtures with Varied $\mathrm{CuCl}_{2}$ Content

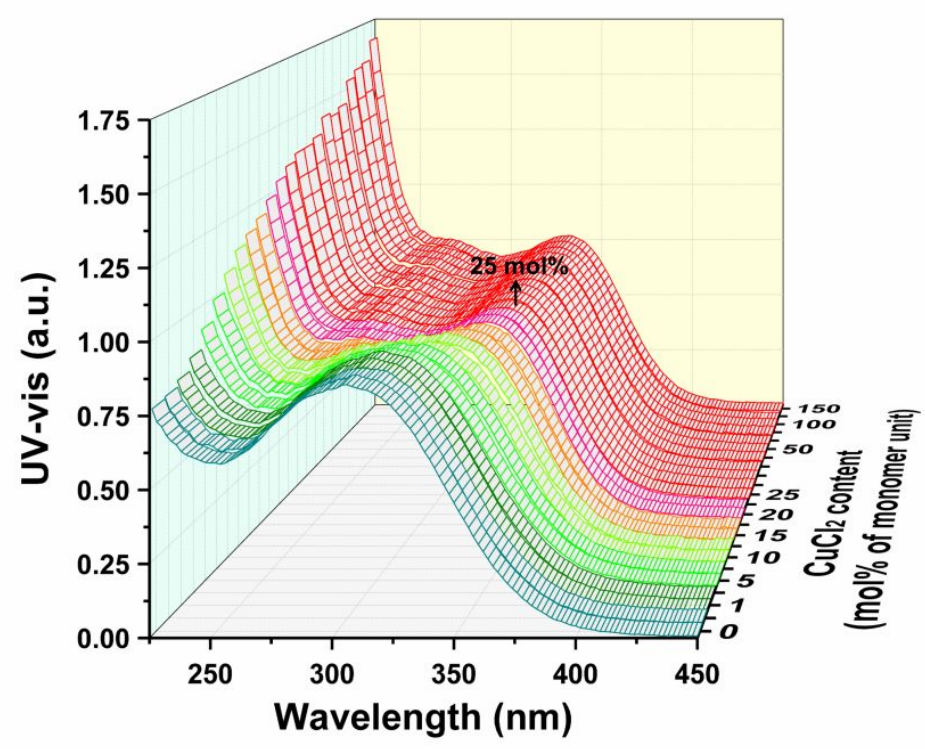

Figure S35. 3D UV-vis absorption spectra of the P-L-ala- $\mathrm{NH}_{2}\left(5 \times 10^{-4} \mathrm{~mol} \mathrm{~L}^{-1}\right.$ by monomer unit) and $\mathrm{CuCl}_{2}$ mixtures with varied $\mathrm{CuCl}_{2}$ content measured in water at $20^{\circ} \mathrm{C}$. All the tested solutions had been allowed to stand still at $20^{\circ} \mathrm{C}$ for over $24 \mathrm{~h}$. 

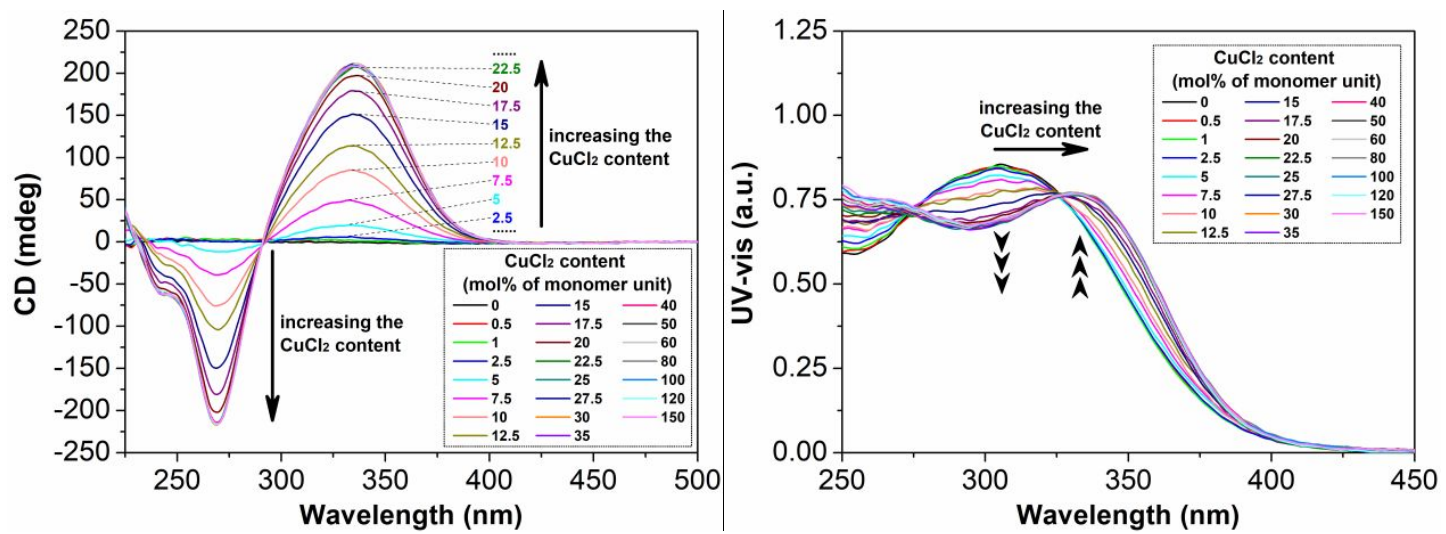

Figure S36. $2 \mathrm{D} \mathrm{CD}$ and UV-vis absorption spectra of the $\mathrm{P}-\mathrm{L}-\mathrm{ala}-\mathrm{NH}_{2}\left(5 \times 10^{-4} \mathrm{~mol}\right.$ $\mathrm{L}^{-1}$ by monomer unit) and $\mathrm{CuCl}_{2}$ mixtures with varied $\mathrm{CuCl}_{2}$ content measured in water at $20^{\circ} \mathrm{C}$. All the tested solutions had been allowed to stand still at $20^{\circ} \mathrm{C}$ for over $24 \mathrm{~h}$.

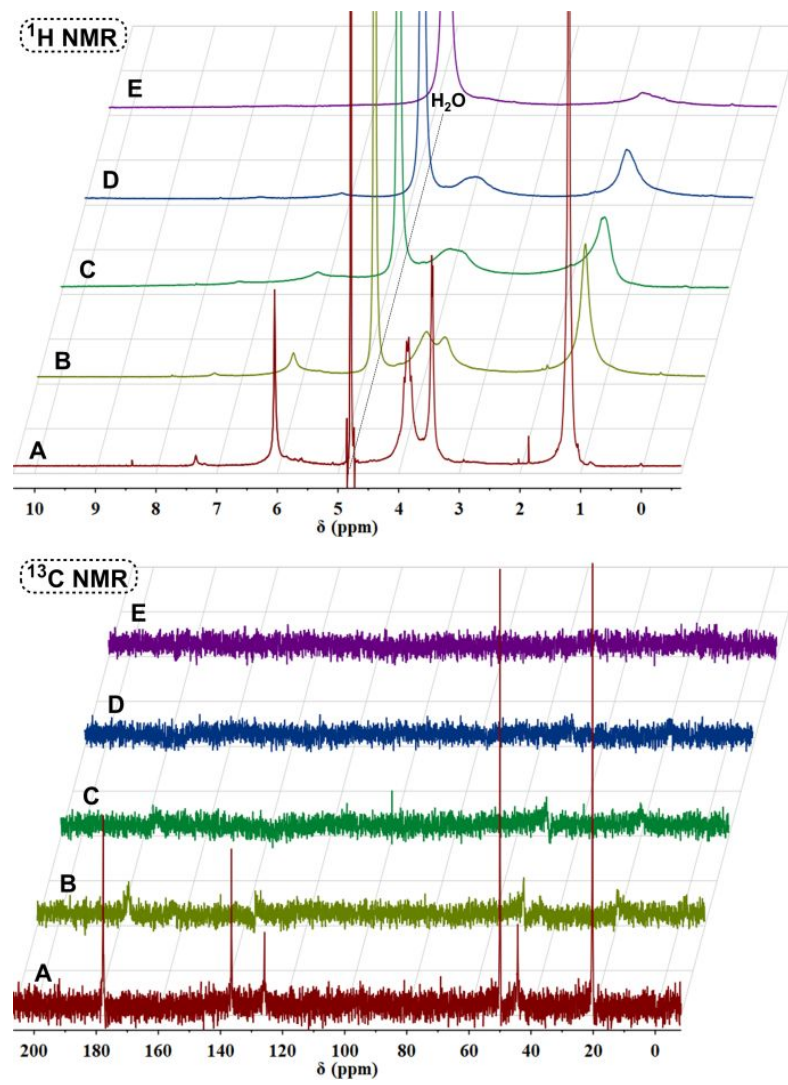

Figure S37. ${ }^{1} \mathrm{H}\left(400 \mathrm{MHz}, 16\right.$ scans) and ${ }^{13} \mathrm{C}(100 \mathrm{MHz}, 5000$ scans $)$ NMR spectra of P-L-ala- $\mathrm{NH}_{2}$ and $\mathrm{CuCl}_{2}$ mixtures with varied $\mathrm{CuCl}_{2}$ content (directly prepared using $\mathrm{D}_{2} \mathrm{O}$, instead of water, as solvent). The $\mathrm{CuCl}_{2}$ contents relative to monomer units were $0 \mathrm{~mol} \%, 5 \mathrm{~mol} \%, 10 \mathrm{~mol} \%, 15 \mathrm{~mol} \%$, and $25 \mathrm{~mol} \%$ in $\mathrm{A}, \mathrm{B}, \mathrm{C}, \mathrm{D}$, and $\mathrm{E}$ respectively. The concentration of P-L-ala- $\mathrm{NH}_{2}$ was kept at $42 \mathrm{mg} / \mathrm{mL}$ in all the samples. 


\section{Resonance Raman Spectra of Pure Polymers}

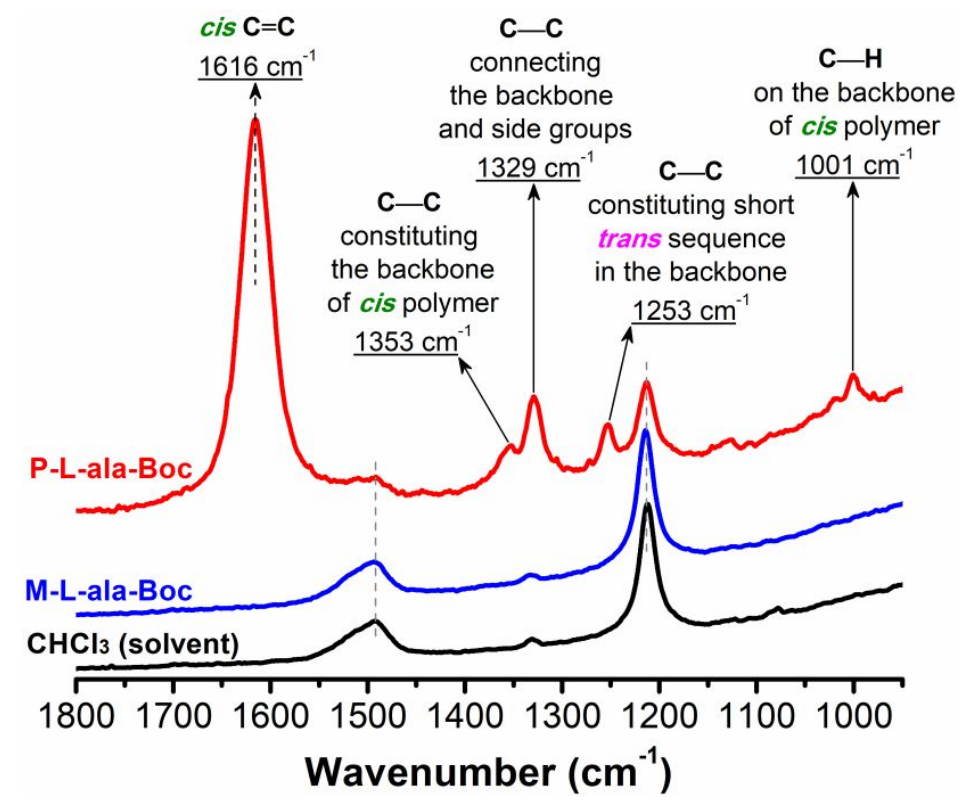

Figure S38. Resonance Raman spectra of TCM and the TCM solutions of M-L-ala-Boc $\left(1 \mathrm{~g} \mathrm{~L}^{-1}\right)$ and P-L-ala-Boc $\left(1 \mathrm{~g} \mathrm{~L}^{-1}\right)$ measured at $20^{\circ} \mathrm{C}$ using a $341.5 \mathrm{~nm}$ excitation laser pulse.

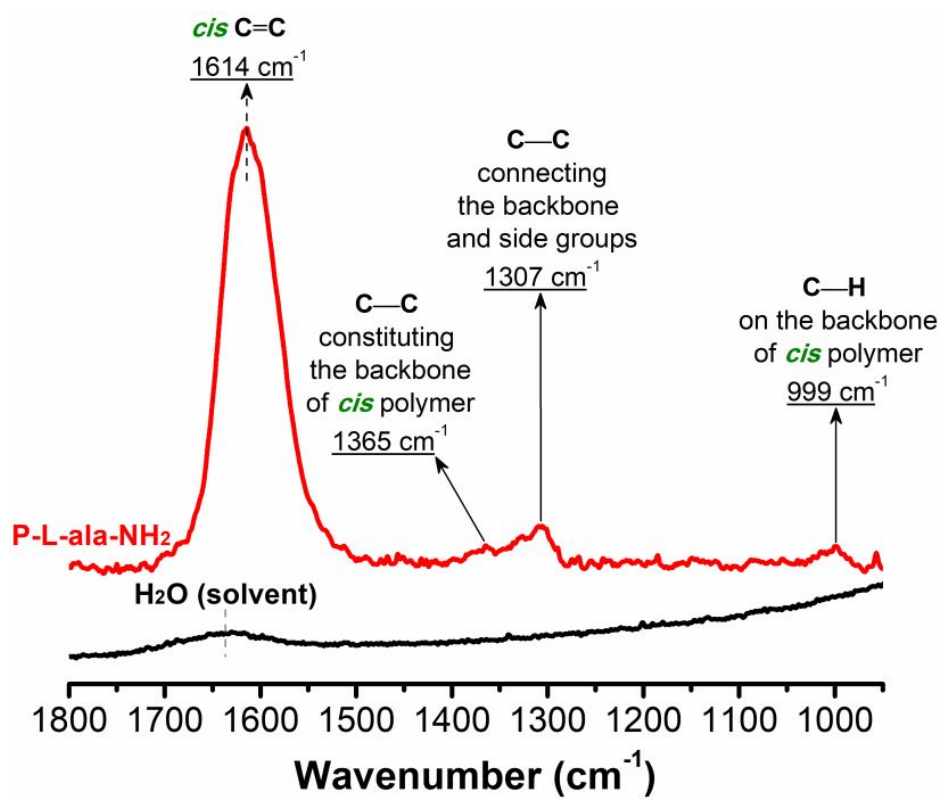

Figure S39. Resonance Raman spectra of water and the water solution of P-L-ala- $\mathrm{NH}_{2}$ $\left(1 \mathrm{~g} \mathrm{~L}^{-1}\right)$ measured at $20^{\circ} \mathrm{C}$ using a $341.5 \mathrm{~nm}$ excitation laser pulse. ${ }^{9}$ 
Resonance Raman Spectra (Full Graph), DSC Traces, XRD Patterns, and FT-IR Spectra of the P-L-ala- $\mathrm{NH}_{2}$ and $\mathrm{CuCl}_{2}$ Mixtures with Varied $\mathrm{CuCl}_{2}$ Content

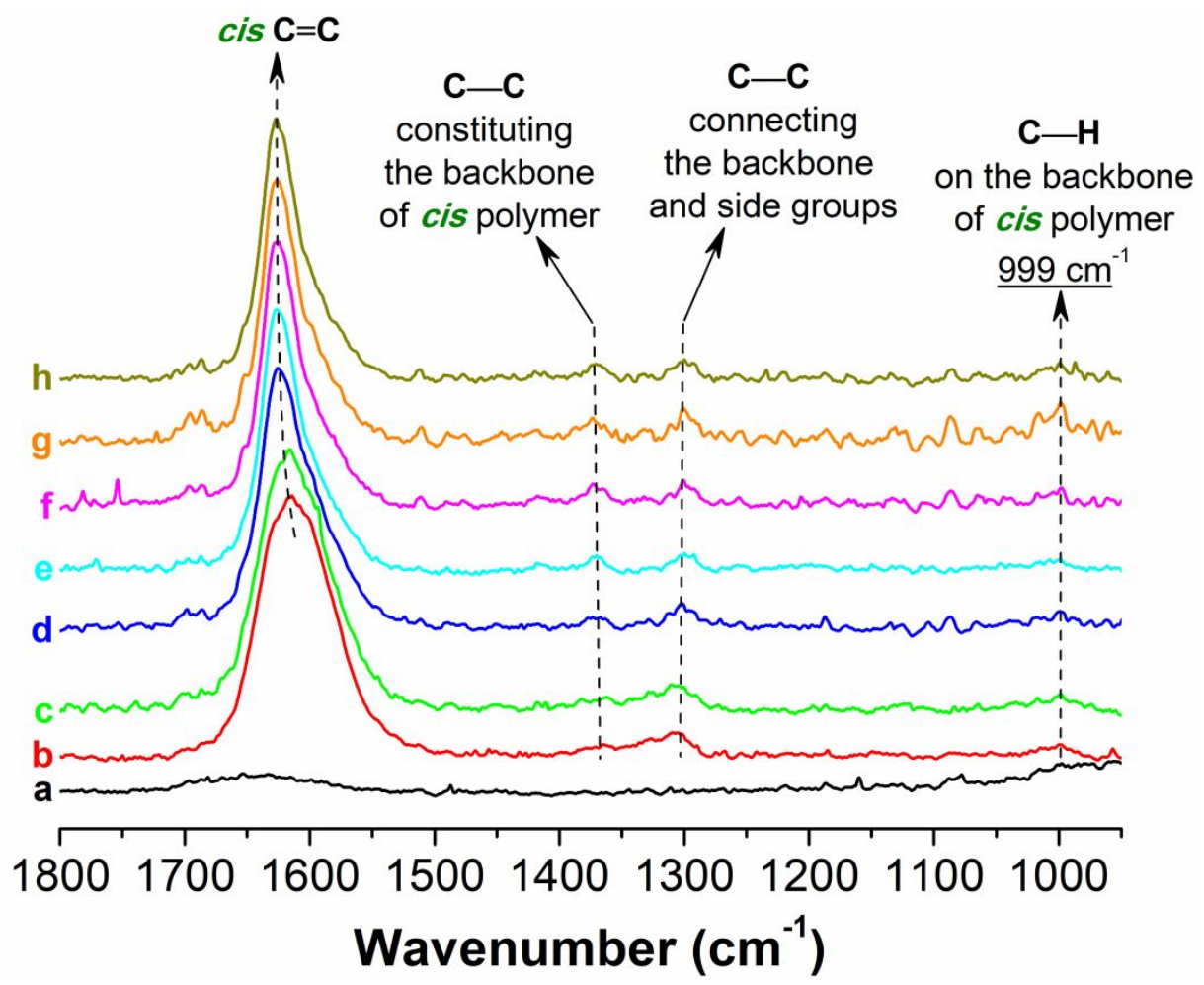

Figure S40. Resonance Raman spectra (full graph) of $\mathrm{CuCl}_{2}$ (a), P-L-ala- $\mathrm{NH}_{2}$ (b), and the mixtures of $\mathrm{P}-\mathrm{L}-\mathrm{ala}-\mathrm{NH}_{2}$ and $\mathrm{CuCl}_{2}$ with varied $\mathrm{CuCl}_{2}$ content (c-h) measured in water at $20^{\circ} \mathrm{C}$ using a $341.5 \mathrm{~nm}$ excitation laser pulse. The concentration of P-L-ala- $\mathrm{NH}_{2}$ and pure $\mathrm{CuCl}_{2}$ was $1 \mathrm{~g} \mathrm{~L}^{-1}$. The $\mathrm{CuCl}_{2}$ contents relative to monomer units were $5 \mathrm{~mol} \%, 10 \mathrm{~mol} \%, 15 \mathrm{~mol} \%, 25 \mathrm{~mol} \%, 60 \mathrm{~mol} \%$, and $100 \mathrm{~mol} \%$ in c, d, e, $\mathrm{f}, \mathrm{g}$, and $\mathrm{h}$ respectively. All the tested solutions had been allowed to stand still at $20^{\circ} \mathrm{C}$ for over $24 \mathrm{~h}$. 


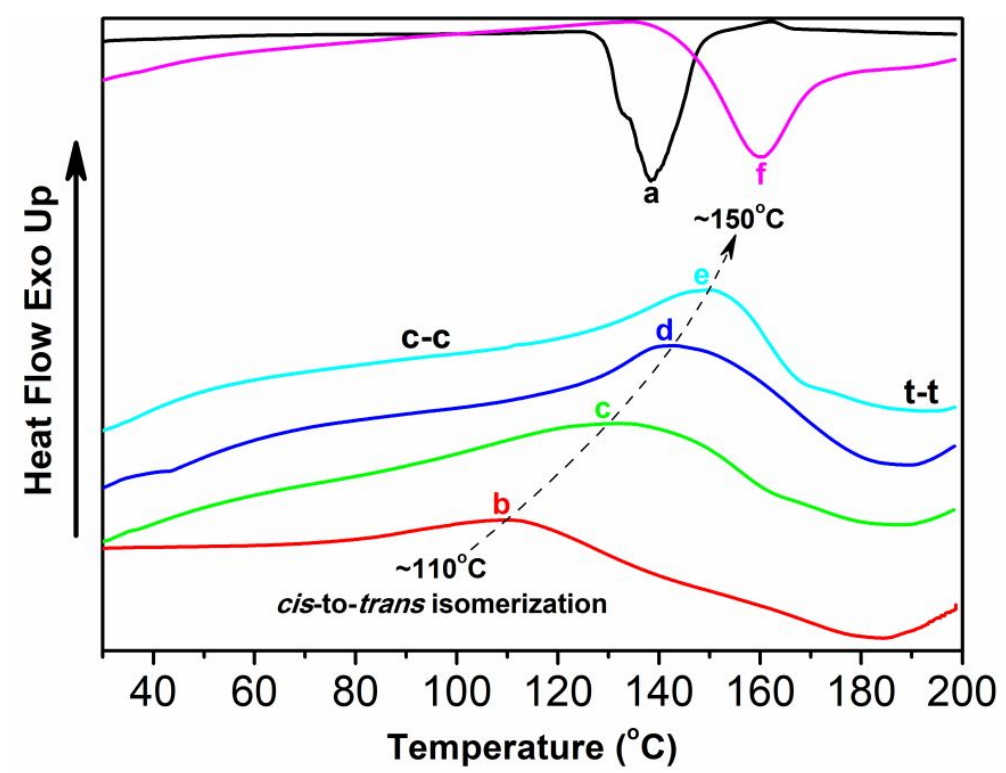

Figure S41. DSC traces $\left(\mathrm{N}_{2}, 10^{\circ} \mathrm{C} \mathrm{min}-1\right)$ of $\mathrm{CuCl}_{2} \cdot 2 \mathrm{H}_{2} \mathrm{O}$ (a), P-L-ala- $\mathrm{NH}_{2}$ (b), and the mixtures of $\mathrm{P}-\mathrm{L}-\mathrm{ala}-\mathrm{NH}_{2}$ and $\mathrm{CuCl}_{2}$ with varied $\mathrm{CuCl}_{2}$ content (c-f) measured in solid state. The solid samples were obtained by reduced pressure distillation (at $50^{\circ} \mathrm{C}$ ) of the solutions used in resonance Raman measurement. The $\mathrm{CuCl}_{2}$ contents relative to monomer units were $10 \mathrm{~mol} \%, 15 \mathrm{~mol} \%, 25 \mathrm{~mol} \%$, and $60 \mathrm{~mol} \%$ in $\mathrm{c}, \mathrm{d}$, e, and $\mathrm{f}$ respectively. The symbols $\mathrm{c}-\mathrm{c}$ and $\mathrm{t}-\mathrm{t}$ refer to cis-cisoid and trans-transoid respectively.

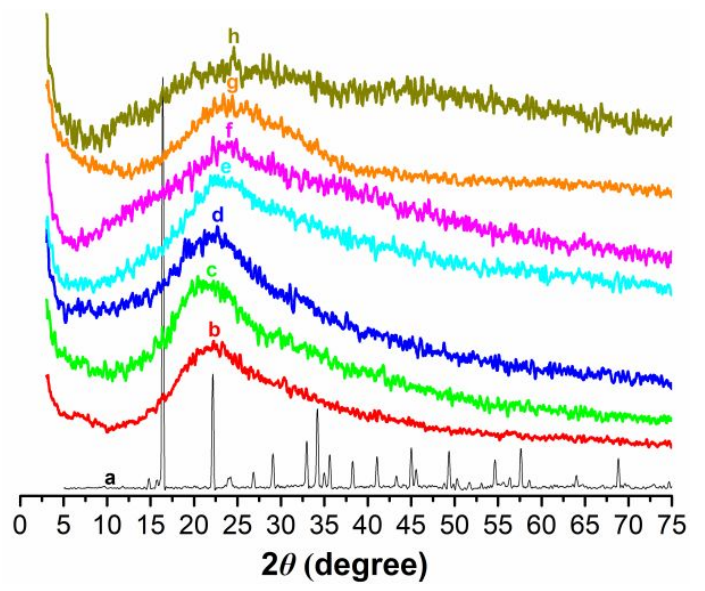

Figure S42. XRD patterns of $\mathrm{CuCl}_{2} \cdot 2 \mathrm{H}_{2} \mathrm{O}$ (a), $\mathrm{P}-\mathrm{L}-\mathrm{ala}-\mathrm{NH}_{2}$ (b), and the mixtures of P-L-ala- $\mathrm{NH}_{2}$ and $\mathrm{CuCl}_{2}$ with varied $\mathrm{CuCl}_{2}$ content (c-h) measured in solid state ( $3^{\circ}-$ $75^{\circ}$ ). The solid samples were obtained by reduced pressure distillation (at $50^{\circ} \mathrm{C}$ ) of the solutions used in resonance Raman measurement. The $\mathrm{CuCl}_{2}$ contents relative to monomer units were $5 \mathrm{~mol} \%, 10 \mathrm{~mol} \%, 15 \mathrm{~mol} \%$, $25 \mathrm{~mol} \%$, $60 \mathrm{~mol} \%$, and $100 \mathrm{~mol} \%$ in $\mathrm{c}, \mathrm{d}, \mathrm{e}, \mathrm{f}, \mathrm{g}$, and $\mathrm{h}$ respectively. 


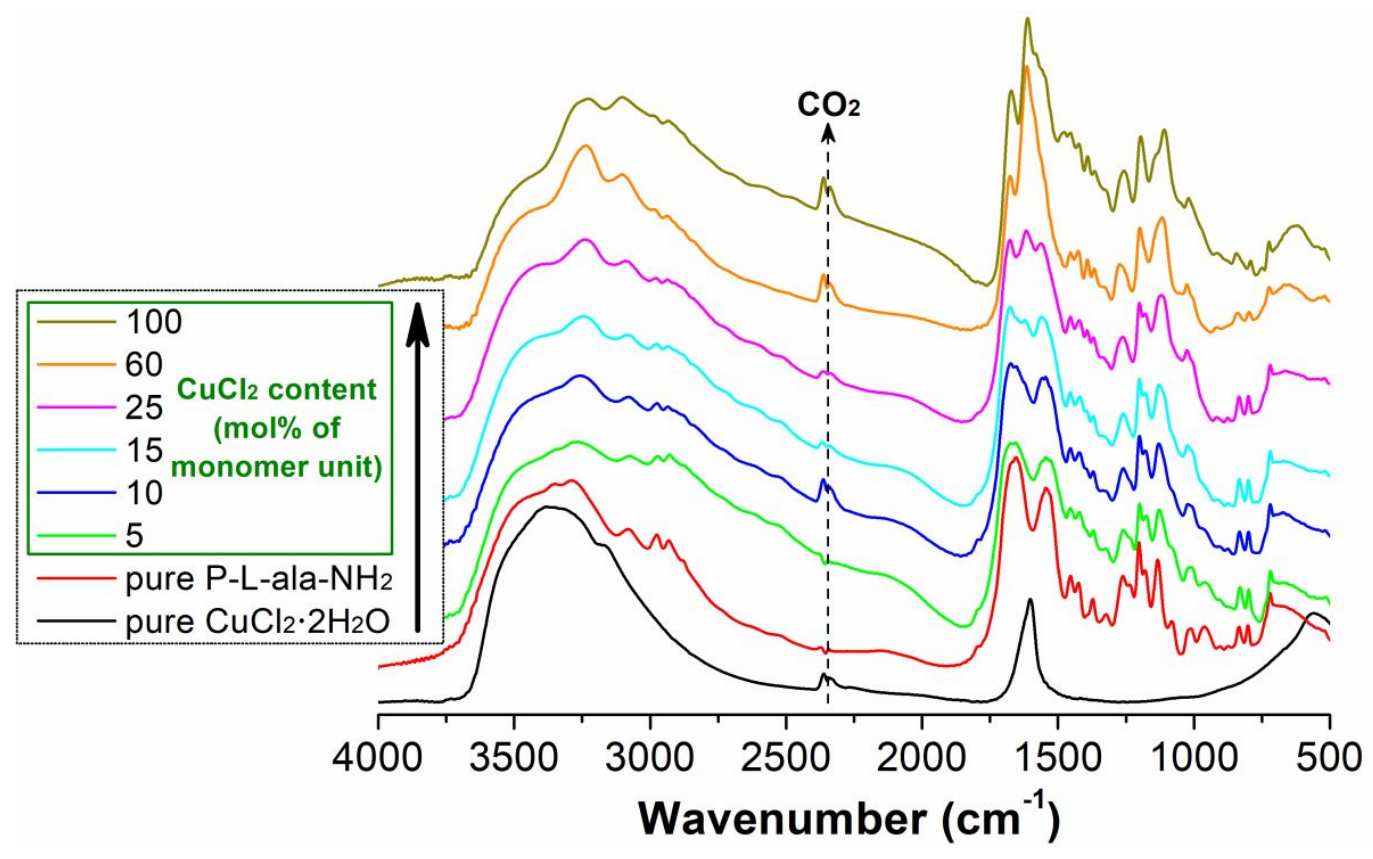

Figure S43. FT-IR spectra (full graph) of $\mathrm{CuCl}_{2} \cdot 2 \mathrm{H}_{2} \mathrm{O}, \mathrm{P}-\mathrm{L}-\mathrm{ala}-\mathrm{NH}_{2}$, and the mixtures of $\mathrm{P}-\mathrm{L}-\mathrm{ala}-\mathrm{NH}_{2}$ and $\mathrm{CuCl}_{2}$ with varied $\mathrm{CuCl}_{2}$ content measured in solid state (KBr tablet). The solid samples were obtained by reduced pressure distillation (at $50^{\circ} \mathrm{C}$ ) of the solutions used in resonance Raman measurement.

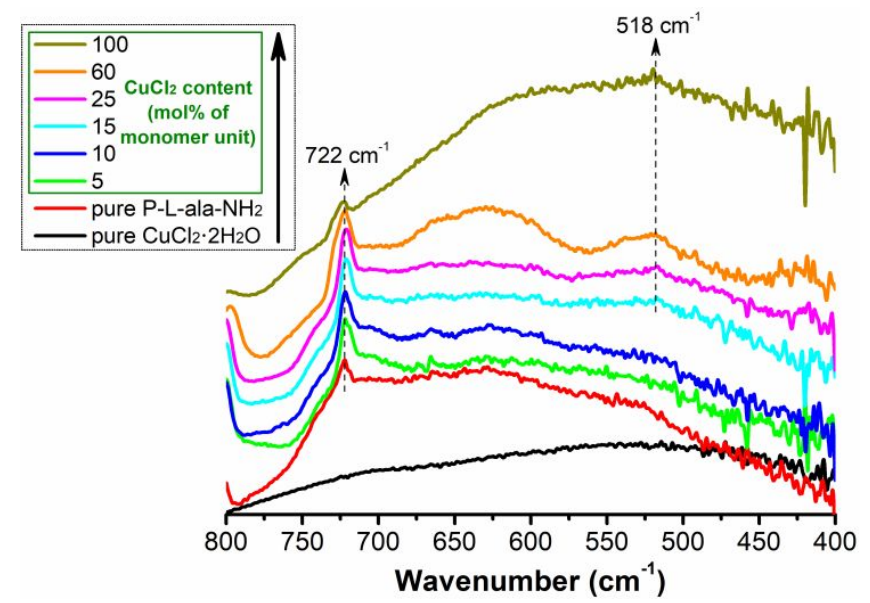

Figure S44. Partial FT-IR spectra $\left(800-400 \mathrm{~cm}^{-1}\right.$ region) of $\mathrm{CuCl}_{2} \cdot 2 \mathrm{H}_{2} \mathrm{O}$, P-L-ala- $\mathrm{NH}_{2}$, and the mixtures of P-L-ala- $\mathrm{NH}_{2}$ and $\mathrm{CuCl}_{2}$ with varied $\mathrm{CuCl}_{2}$ content measured in solid state ( $\mathrm{KBr}$ tablet). The solid samples were obtained by reduced pressure distillation (at $50^{\circ} \mathrm{C}$ ) of the solutions used in resonance Raman measurement. 


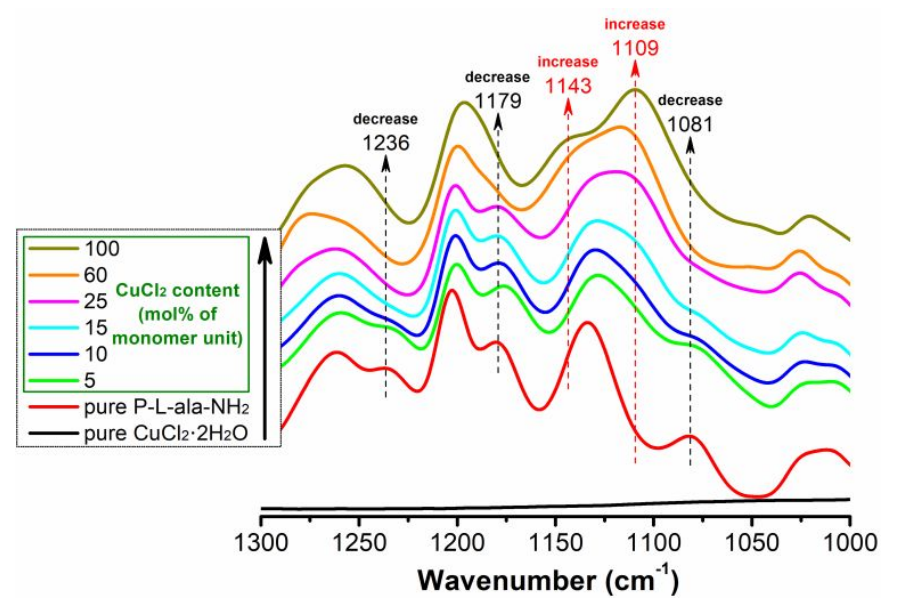

Figure S45. Partial FT-IR spectra $\left(1300-1000 \mathrm{~cm}^{-1}\right.$ region) of $\mathrm{CuCl}_{2} \cdot 2 \mathrm{H}_{2} \mathrm{O}$, P-L-ala- $\mathrm{NH}_{2}$, and the mixtures of P-L-ala- $\mathrm{NH}_{2}$ and $\mathrm{CuCl}_{2}$ with varied $\mathrm{CuCl}_{2}$ content measured in solid state ( $\mathrm{KBr}$ tablet). The solid samples were obtained by reduced pressure distillation (at $50^{\circ} \mathrm{C}$ ) of the solutions used in resonance Raman measurement.

\section{CD and UV-vis Absorption Spectra of P-L-ala-NH ${ }_{3}^{+} \mathrm{TFA}^{-}$in the Presence of $\mathrm{Ag}^{+}$}

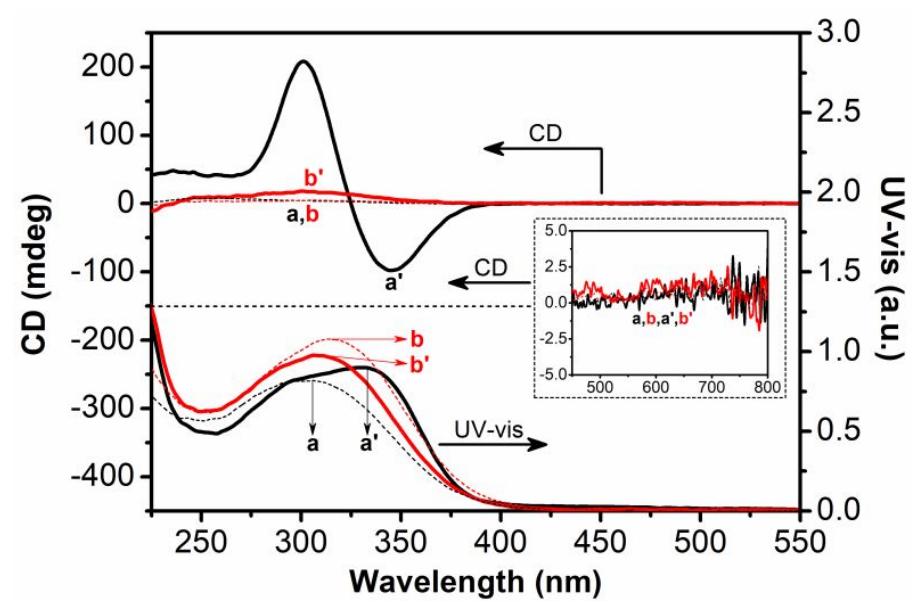

Figure S46. $\mathrm{CD}$ and UV-vis absorption spectra of P-L-ala- $\mathrm{NH}_{2}$ (a), P-L-ala- $\mathrm{NH}_{3}{ }^{+} \mathrm{TFA}^{-}$(b), the equimolar (by monomer unit) mixture of P-L-ala- $\mathrm{NH}_{2}$ and $\mathrm{Ag}_{2} \mathrm{SO}_{4}$ (a'), and the equimolar (by monomer unit) mixture of $\mathrm{P}-\mathrm{L}-\mathrm{ala}-\mathrm{NH}_{3}{ }^{+} \mathrm{TFA}^{-}$and $\mathrm{Ag}_{2} \mathrm{SO}_{4}$ (b') measured in water at $20^{\circ} \mathrm{C}$ (polymer concentration $=5 \times 10^{-4} \mathrm{~mol} \mathrm{~L}^{-1}$ by monomer unit). All the tested solutions had been allowed to stand still at $20^{\circ} \mathrm{C}$ for over $24 \mathrm{~h}$. 


\section{Effect of pH on the Induced Helical Structure}
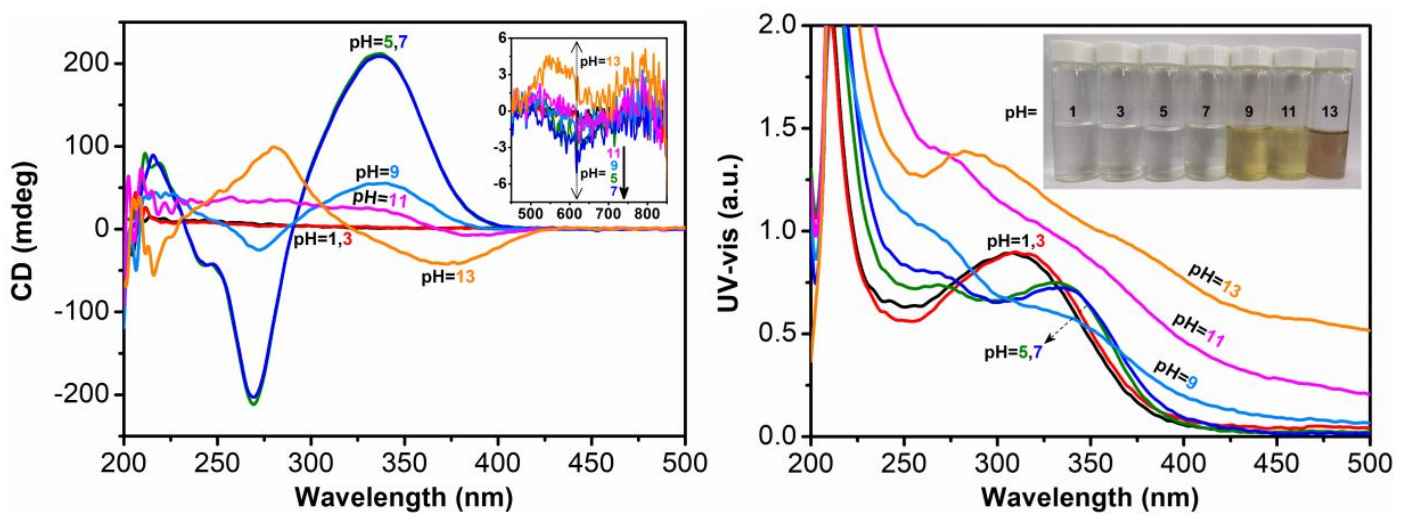

Figure S47. $\mathrm{CD}$ and $\mathrm{UV}$-vis absorption spectra of $\mathrm{P}-\mathrm{L}$-ala- $\mathrm{NH}_{2}$ and $\mathrm{CuCl}_{2}$ equimolar (by monomer unit) water solution measured at $20^{\circ} \mathrm{C}$ under varied $\mathrm{pH}$ (polymer concentration $\approx 5 \times 10^{-4}$ mol L-1 by monomer unit). All the tested solutions had been allowed to stand still at $20^{\circ} \mathrm{C}$ for over $24 \mathrm{~h}$.

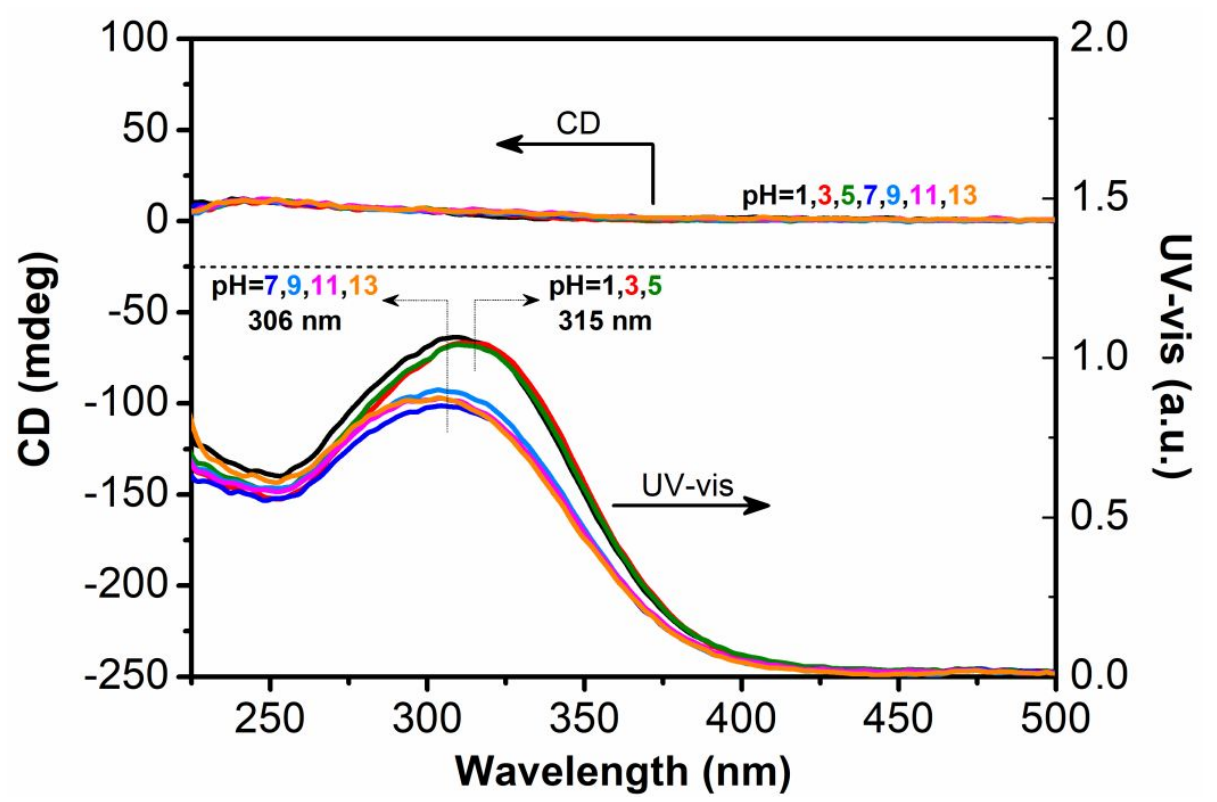

Figure S48. CD and UV-vis absorption spectra of P-L-ala- $\mathrm{NH}_{2}$ measured at $20^{\circ} \mathrm{C}$ in water under varied $\mathrm{pH}$ (concentration $\approx 5 \times 10^{-4} \mathrm{~mol} \mathrm{~L}^{-1}$ by monomer unit). 
CD and Vis-NIR Absorption Spectra of M-L-ala-NH $/ \mathrm{Cu}^{2+}, \mathrm{M}-\mathrm{D}-\mathrm{ala}-\mathrm{NH}_{2} / \mathrm{Cu}^{2+}$, and D-alaninamide/ $\mathrm{Cu}^{2+} \mathrm{Complexes}$

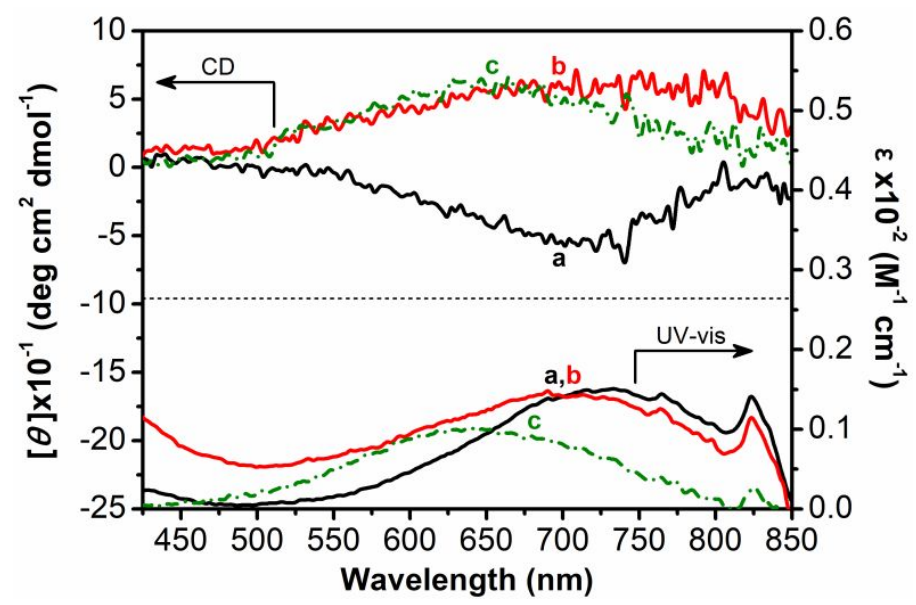

Figure S49. CD and vis-NIR absorption spectra of equimolar mixture of M-L-ala- $\mathrm{NH}_{2}$ and $\mathrm{CuCl}_{2}$ (a), equimolar mixture of $\mathrm{M}-\mathrm{D}-\mathrm{ala}-\mathrm{NH}_{2}$ and $\mathrm{CuCl}_{2}(\mathrm{~b})$, and equimolar mixture of D-alaninamide and $\mathrm{CuCl}_{2}$ (c) measured in water at $20^{\circ} \mathrm{C}$ (concentration $=10^{-2} \mathrm{~mol} \mathrm{~L}^{-1}$ ). All the tested solutions had been allowed to stand still at $20^{\circ} \mathrm{C}$ for over $24 \mathrm{~h}$.

\section{Effect of Metal Scavenger and Dilution on the Induced Helical Structure}

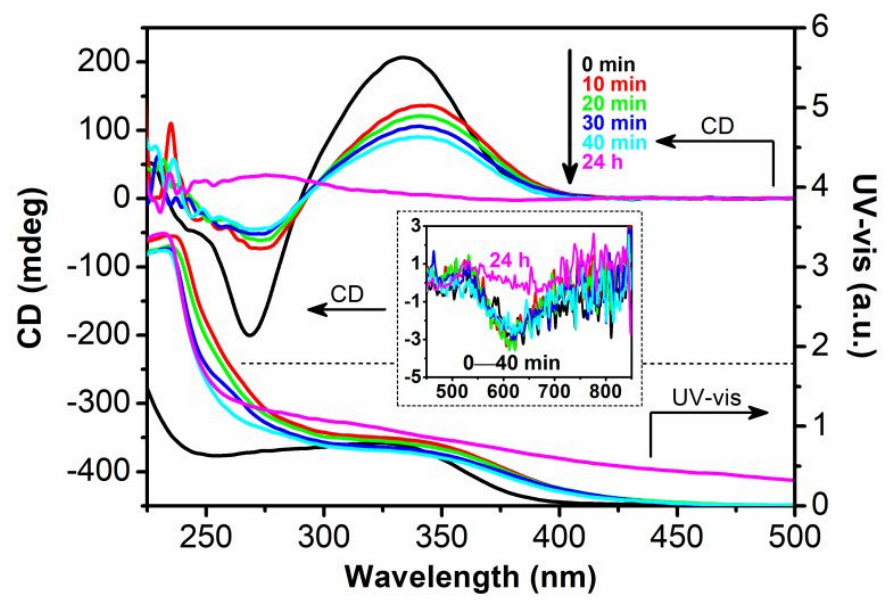

Figure S50. Time-dependent $\mathrm{CD}$ and UV-vis absorption spectra of $\mathrm{P}-\mathrm{L}-\mathrm{ala}-\mathrm{NH}_{2}$ and $\mathrm{CuCl}_{2}$ equimolar water solution measured at $20^{\circ} \mathrm{C}$ after adding 100 equiv of triethylamine (polymer concentration $=5 \times 10^{-4} \mathrm{~mol} \mathrm{~L}^{-1}$ ). The concentration and molar ratios were calculated based on monomer unit. 


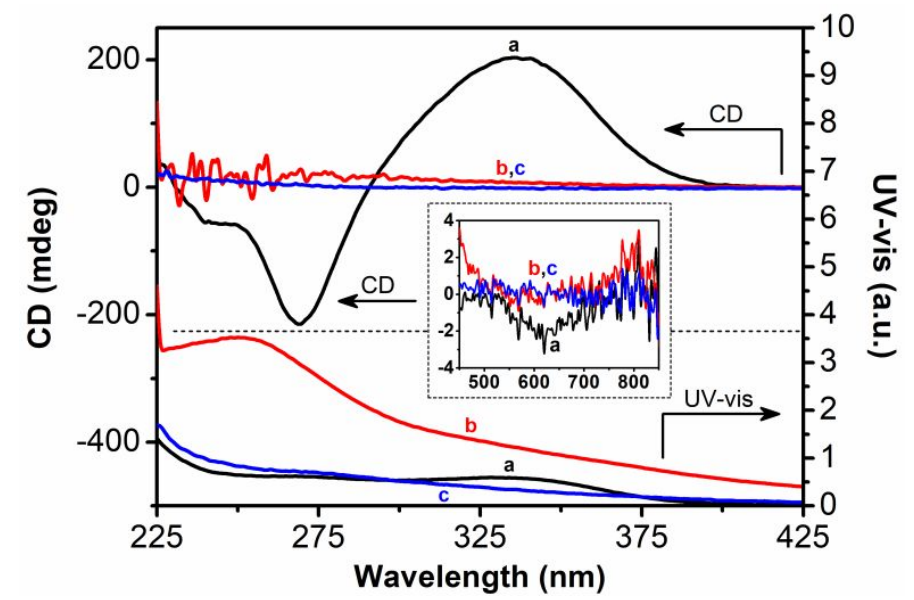

Figure S51. CD and UV-vis absorption spectra of $\mathrm{P}-\mathrm{L}$-ala- $\mathrm{NH}_{2}$ and $\mathrm{CuCl}_{2}$ equimolar water solution before (a) and immediately after $(b, c)$ adding 10 equiv of $\mathrm{Na}_{2} \mathrm{~S}$ measured at $20^{\circ} \mathrm{C}$ (polymer concentration in (a) and (b) $=5 \times 10^{-4} \mathrm{~mol} \mathrm{~L}^{-1}$; polymer concentration in $(\mathrm{c})=10^{-4} \mathrm{~mol} \mathrm{L^{-1 }}$ ). All the concentrations and molar ratios were calculated based on monomer unit.

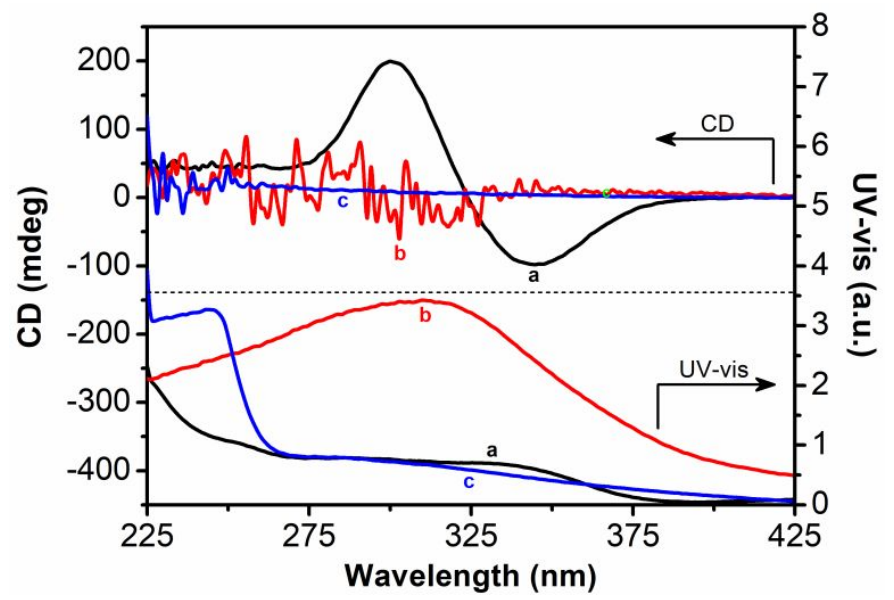

Figure S52. $\mathrm{CD}$ and UV-vis absorption spectra of P-L-ala- $\mathrm{NH}_{2}$ and $\mathrm{Ag}_{2} \mathrm{SO}_{4}$ equimolar water solution before (a) and immediately after (b,c) adding 10 equiv of $\mathrm{Na}_{2} \mathrm{~S}$ measured at $20^{\circ} \mathrm{C}$ (polymer concentration in (a) and (b) $=5 \times 10^{-4} \mathrm{~mol} \mathrm{~L}^{-1}$; polymer concentration in $\left.(\mathrm{c})=10^{-4} \mathrm{~mol} \mathrm{~L}^{-1}\right)$. All the concentrations and molar ratios were calculated based on monomer unit. 

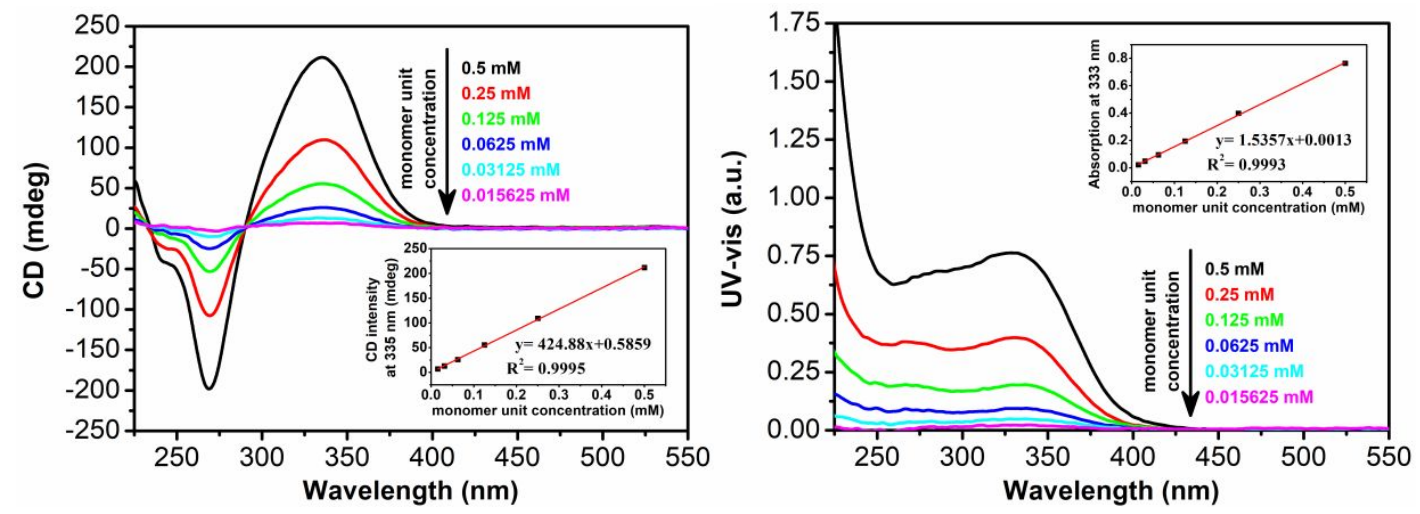

Figure S53. $\mathrm{CD}$ and $\mathrm{UV}$-vis absorption spectra of $\mathrm{P}-\mathrm{L}-\mathrm{ala}-\mathrm{NH}_{2}$ and $\mathrm{CuCl}_{2}$ equimolar (by monomer unit) water solution measured at $20^{\circ} \mathrm{C}$ under varied concentrations. All the concentrations were calculated based on monomer unit. All the tested solutions had been allowed to stand still at $20^{\circ} \mathrm{C}$ for over $24 \mathrm{~h}$. 


\section{Supporting References and Notes}

(1) Schrock, R. R.; Osborn, J. A. $\pi$-Bonded Complexes of the Tetraphenylborate Ion with Rhodium (I) and Iridium (I). Inorg. Chem. 1970, 9, 2339-2343.

(2) Ouyang, B.; Xue, J. D.; Zheng, X.; Fang, W. H. Structural Dynamics of Phenylisothiocyanate in the Light-Absorbing Excited States: Resonance Raman and Complete Active Space Self-Consistent Field Calculation Study. J. Chem. Phys. 2014, $140,194305$.

(3) Gao, G.; Sanda, F.; Masuda, T. Synthesis and Properties of Amino Acid-Based Polyacetylenes. Macromolecules 2003, 36, 3932-3937.

(4) Gao, G.; Sanda, F.; Masuda, T. Copolymerization of Chiral Amino Acid-Based Acetylenes and Helical Conformation of the Copolymers. Macromolecules 2003, 36, $3938-3943$.

(5) The signal of cis-olefinic protons in the main-chain of P-L-ala- $\mathrm{NH}_{3}{ }^{+} \mathrm{TFA}^{-}$ (labeled as a) appeared near $6 \mathrm{ppm}$. Accordingly, the cis $\mathrm{C}=\mathrm{C}$ content of P-L-ala- $\mathrm{NH}_{3}{ }^{+} \mathrm{TFA}^{-}$was calculated to be $90 \%$ by the following equation:

$$
\text { cis } \mathrm{C}=\mathrm{C} \text { content }(\%)=3 \times \mathrm{A}_{\mathrm{a}} /\left(\mathrm{A}_{\mathrm{b}}+\mathrm{A}_{\mathrm{c}}\right) \text {, }
$$

where A represents the integral area of the indicated protons.

(6) The signal of cis-olefinic protons in the main-chain of P-L-ala- $\mathrm{NH}_{2}$ (labeled as a) appeared at about $6 \mathrm{ppm}$. Accordingly, the cis $\mathrm{C}=\mathrm{C}$ content of $\mathrm{P}-\mathrm{L}-\mathrm{ala}-\mathrm{NH}_{2}$ was calculated to be $90 \%$ by the following equation:

$$
\text { cis } \mathrm{C}=\mathrm{C} \text { content }(\%)=3 \times \mathrm{A}_{\mathrm{a}} /\left(\mathrm{A}_{\mathrm{b}}+\mathrm{A}_{\mathrm{c}}\right) \text {, }
$$

where A represents the integral area of the indicated protons. 
(7) In ${ }^{1} \mathrm{H}$ NMR spectra, all the protons in P-L-ala- $\mathrm{NH}_{3}{ }^{+} \mathrm{TFA}^{-}$underwent upfield shift after deprotonation due to the stronger electron-donating effect of $-\mathrm{NH}_{2}$ compared with that of $-\mathrm{NH}_{3}{ }^{+}$. In ${ }^{13} \mathrm{C}$ NMR spectra, the carbons near $-\mathrm{NH}_{3}{ }^{+}$(especially the $\beta$-carbons indicated by $\mathbf{d}$ and $\mathbf{f}$ ) underwent downfield shift after deprotonation due to the removal of electric field effect of $-\mathrm{NH}_{3}{ }^{+}$.

(8) The two spectra are almost identical, demonstrating the successful preparation of $\mathrm{P}-\mathrm{L}=\mathrm{D}-$ ala- $\mathrm{NH}_{2}$.

(9) The Raman peak of $\mathrm{C}-\mathrm{C}$ bonds on the short trans sequences of P-L-ala- $\mathrm{NH}_{2}$ main-chain was not observed due to some unknown structural reasons. A possible explanation is that the short trans sequences may play special roles, such as helix-reversal points, in determining the overall structure of P-L-ala-Boc, but only act as ordinary segments in the random coil P-L-ala- $\mathrm{NH}_{2}$. 